\title{
Activation of Dopaminergic D2/D3 Receptors Modulates Dorsoventral Connectivity in the Hippocampus and Reverses the Impairment of Working Memory after Nerve Injury
}

\author{
Helder Cardoso-Cruz, ${ }^{1,2 *}$ Margarida Dourado, ${ }^{1,2,3 *}$ Clara Monteiro, ${ }^{1,2}$ Mariana R. Matos, ${ }^{1,2}$ and Vasco Galhardo ${ }^{1,2}$ \\ ${ }^{1}$ Departamento de Biologia Experimental, Faculdade de Medicina, Universidade do Porto, 4200-319 Porto, Portugal, ${ }^{2}$ Instituto de Biologia Molecular e \\ Celular, Grupo de Morfofisiologia do Sistema Somatosensitivo, Universidade do Porto, 4150-180 Porto, Portugal, and ${ }^{3}$ Programa Doutoral em \\ Neurociências, Faculdade de Medicina, Universidade do Porto. 4200-319 Porto, Portugal
}

\begin{abstract}
Dopamine plays an important role in several forms of synaptic plasticity in the hippocampus, a crucial brain structure for working memory (WM) functioning. In this study, we evaluated whether the working-memory impairment characteristic of animal models of chronic pain is dependent on hippocampal dopaminergic signaling. To address this issue, we implanted multichannel arrays of electrodes in the dorsal and ventral hippocampal CA1 region of rats and recorded the neuronal activity during a food-reinforced spatial WM task of trajectory alternation. Within-subject behavioral performance and patterns of dorsoventral neuronal activity were assessed before and after the onset of persistent neuropathic pain using the Spared Nerve Injury (SNI) model of neuropathic pain. Our results show that the peripheral nerve lesion caused a disruption in WM and in hippocampus spike activity and that this disruption was reversed by the systemic administration of the dopamine D2/D3 receptor agonist quinpirole $(0.05 \mathrm{mg} / \mathrm{kg})$. In SNI animals, the administration of quinpirole restored both the performance-related and the task-related spike activity to the normal range characteristic of naive animals, whereas quinpirole in sham animals caused the opposite effect. Quinpirole also reversed the abnormally low levels of hippocampus dorsoventral connectivity and phase coherence. Together with our finding of changes in gene expression of dopamine receptors and modulators after the onset of the nerve injury model, these results suggest that disruption of the dopaminergic balance in the hippocampus may be crucial for the clinical neurological and cognitive deficits observed in patients with painful syndromes.
\end{abstract}

Key words: awake animal physiology; dopamine; hippocampus; neuropathy; pain; working memory

\section{Introduction}

The differential processing of working memory (WM) between hippocampal regions is a topic of renewed interest because it is still not understood how cognitive salient information is distributed along the dorsoventral axis of the hippocampus (Fanselow and Dong, 2010). Although neuroanatomical (Swanson and Cowan, 1977; Witter and Amaral, 2004), functional (Bannerman et al., 1999; Kjelstrup et al., 2002), and gene expression (Thompson et al., 2008; Dong et al., 2009) studies support the notion of a functional separation between the entorhinal-dorsal hippocampus circuit and the amygdala-ventral hippocampus circuit

\footnotetext{
Received Jan. 2, 2014; revised Feb. 25, 2014; accepted Feb. $28,2014$.

Author contributions: H.C.-C., M.D., C.M., and V.G. designed research; H.C.-C., M.D., C.M., and M.R.M. performed research; H.C.-C., M.D., C.M., M.R.M., and V.G. analyzed data; H.C.-C., M.D., C.M., and V.G. wrote the paper.

This work was supported by FEDER funds through the Operational Competitiveness Programme-COMPETE, National Funds through Fundação para a Ciência e a Tecnologia (Project FCOMP-01-0124-FEDER-011202, Grant PTDC/SAU-NEU/100773/2008; Project FCOMP-01-0124-FEDER-029686, Grant PTDC/NEU-SCC/1516/2012; and Doctoral Grant SFRH/42500/2007), and the BIAL Foundation (Project 126/08).

The authors declare no competing financial interests.

*H.C.-C. and M.D. contributed equally to this work.

Correspondence should be addressed to Vasco Galhardo, PhD, Departamento de Biologia Experimental, Faculdade de Medicina da Universidade do Porto, Alameda Prof Hernani Monteiro, 4200 -319 Porto, Portugal. E-mail: galhardo@med.up.pt.

DOI:10.1523/JNEUROSCI.0021-14.2014

Copyright $\odot 2014$ the authors $\quad 0270-6474 / 14 / 345861-13 \$ 15.00 / 0$
}

(Moser and Moser, 1998), few studies have simultaneously recorded both areas during spatial WM tasks (Schmidt et al., 2013).

We have shown recently that chronic pain disrupts place cell activity in the hippocampus (Cardoso-Cruz et al., 2011a) and leads to a decrease in functional connectivity between the medial prefrontal and the hippocampus during performance in spatial WM tasks (Cardoso-Cruz et al., 2013a); however, these results relate only to the dorsal hippocampus and it is still not known whether the neural activity in ventral hippocampus is also affected in chronic pain models.

Dopaminergic transmission has a vital influence on WM (Arnsten et al., 1995; Cai and Arnsten, 1997; Castner et al., 2000) and dopamine within the dorsal hippocampus is known to be particularly important for the establishment of the longer forms of LTP (Lisman et al., 2011). Interestingly, it has been shown in both animal and human chronic pain syndromes that there is a decrease in the tonic levels of dopamine in brain areas such as the prefrontal cortex, striatum, and hippocampus (Wood et al., 2007a; Wood et al., 2007b; Pais-Vieira et al., 2009), whereas there is some evidence of a correlation between a decrease in reduced dopamine activity and a decrease in hippocampal gray matter in chronic pain patients (Wood et al., 2009).

Pharmacological studies have shown that specific D2-family agonists can improve memory retention and WM in delay- 
dependent tasks (Packard and White, 1991; Gasbarri et al., 1993; Wilkerson and Levin, 1999). More importantly, recent data showed that D2 receptors in the hippocampus contribute not only to memory functions (Takahashi et al., 2008), but also to interactions in the frontohippocampus circuit that are crucial for information retention in a wide range of cognitive processes such as spatial WM (Rainer and Miller, 2000). This raises the hypothesis that changes in hippocampus dopaminergic transmission may have, not only an important local effect, but also may influence brain areas that are modulated directly by hippocampus activity. Despite all of the knowledge gathered in recent years, it remains unclear whether chronic pain affects the hippocampal dopaminergic transmission and if that translates to a disruption of the information processing that is crucial needed for spatial mnemonic processing. Therefore, in this study, we investigated whether activation of dopamine $\mathrm{D} 2 / \mathrm{D} 3$ receptors during performance in a spatial alternation WM task affects hippocampus dorsoventral functional connectivity and individual neuron encoding.

\section{Materials and Methods}

\section{Animals and ethical statement}

Experiments were performed in 31 Sprague Dawley adult male rats (weight 275-325 g; Charles River Laboratories). Before surgery, animals were housed in collective cages (three per box) and kept on a $12 \mathrm{~h} \mathrm{light/}$ dark cycle. Training and recording sessions were performed at approximately the same time each day during the light portion of the cycle. During the course of the experiments, all animals were food deprived to $90-95 \%$ of their ad libitum feeding body weights. All electrophysiological and behavioral studies were performed in accordance with the guidelines of the European Union (2010/63/CE) and with the Research and Ethical Issues of the International Association for the Study of Pain (Zimmermann, 1983). The experimental protocols were also approved by the local Ethical Committee for Animal Use and national Direcção Geral de Alimentação e Veterinária board (Lisbon, Portugal). At least one category C Federation of European Laboratory Animal Science Associations (FELASA)-certified experimenter was present when animals were manipulated.

\section{Implantation of electrodes and nerve lesion model}

The procedure for the surgical implantation of intracranial multielectrode arrays has been described previously in detail (Cardoso-Cruz et al., 2011b). Briefly, animals were anesthetized with a ketamine/medetomidine mixture ( 75 and $0.5 \mathrm{mg} / \mathrm{kg}$ in saline, respectively, i.p.). Anesthesia was maintained with small additional injections of ketamine (one-third of the initial dosage). Depth of anesthesia and paralysis of the musculature were assessed by regular testing of corneal blink, hind-paw withdrawal, and tail-pinch reflexes. Core body temperature was measured with rectal thermometer and maintained at $37^{\circ} \mathrm{C}$ using a homeothermic blanket system (Harvard Apparatus). Animals were secured in a stereotaxic frame using ear bars and the skull was exposed and cleaned using hydrogen peroxide. Holes were bored in the skull for entry points of the two microelectrode arrays and to secure four to five screws necessary to hold the arrays and for grounding purposes. Each microelectrode array contained eight filaments of isonel-coated tungsten wire (35 $\mu \mathrm{m}$ in diameter; California Fine Wire Company) with impedances varying between 0.5 and $0.7 \mathrm{M} \Omega$ at $1 \mathrm{kHz}$. The multielectrode arrays were assembled in a $4 \times 2$ architecture, with spacing of $250 \mu \mathrm{m}$ between filaments and $450 \mu \mathrm{m}$ between each row (Cardoso-Cruz et al., 2011a). The arrays were oriented rostrocaudally and mounted in the holder of a hydraulic micropositioner (FHC) and subsequently slowly driven (50 $\mu \mathrm{m} / \mathrm{min}$ ) to the dorsal hippocampus ( $\mathrm{dCA} 1$ ) and ventral hippocampus ( $\mathrm{vCA1}$ ). The following coordinates in millimeters relative to bregma (Paxinos and Watson, 1998) were used to place the electrode arrays: $\mathrm{dCAl},-3.2$ rostrocaudal, \pm 2.2 mediolateral, -2.7 dorsoventral; $\mathrm{vCAl}$, -6.0 rostrocaudal, \pm 5.5 mediolateral, -7.5 dorsoventral. The multielectrode arrays were implanted unilaterally and counterbalanced between animals.

\section{Spared nerve injury}

In the same intervention and immediately after the implantation of the electrodes each animal was subjected to the Spared Nerve Injury (SNI) model of neuropathic pain (Decosterd and Woolf, 2000; SNI group, $n=$ 7) or to a sham intervention (sham group, $n=4$ ) involving the same extent of skin incision and muscle dissection. SNI surgery consists of the ligation and transaction of the tibial and common peroneal branches of the sciatic nerve while sparing the sural nerve. Both interventions were done on the hindpaw contralateral to the side of implantation of the recording arrays. Sensory threshold for noxious mechanical stimulation was measured $1 \mathrm{~h}$ after the end of the behavioral or recording session using von Frey filaments (Somedic, Sweden) as described previously (Chaplan et al., 1994; Cardoso-Cruz et al., 2011a).

After surgery, rats were allowed to recover for $7 \mathrm{~d}$ before behavioral and recording sessions began. During this recovery period, each animal was placed in the testing room daily and connected to a W16 wireless head-stage transmitter (Triangle Biosystems) to adapt to the recording conditions in the laboratory environment.

\section{Behavioral procedures}

Figure-8 maze. In this study, we evaluated spatial WM performance using a food-reinforced spatial alternation task on a figure-8-shaped maze (Cardoso-Cruz et al., 2013a; Fig. 1B). The total dimension of the arena was $90 \times 60 \mathrm{~cm}$, with Plexiglas corridors $15 \mathrm{~cm}$ wide and opaque walls 30 $\mathrm{cm}$ high. Starting from the center of the maze $(\mathrm{C})$, the rats were trained to alternately visit two reward sites (R) to obtain one chocolate-flavored pellet $(45 \mathrm{mg}$ ) that was automatically delivered by a pellet dispenser (Coulbourn Instruments). After visiting one of the reward locations, the animal had to continue forward and cross again the central corridor before visiting the opposite reward site; food rewards were not dispensed if the animal failed to cross the central corridor immediately before arriving at the reward sites or if the animal made two consecutive visits to the same reward site. Control of pellet dispensers was fully automated using the OpenControl software adapted to this particular task (Aguiar et al., 2007). In all of the analyses in this study, we considered three different zones in the behavioral arena: "reward zones" were the $15 \times 15 \mathrm{~cm}$ corner areas where the animal received a pellet upon a correct alternation; the "delay zones" were the area between the reward zones and the central corridor; and the "choice zone" was the area preceding the reward zones and immediately after the central corridor (Cardoso-Cruz et al., 2013a).

Experimental timeline. After the $7 \mathrm{~d}$ recovery period following surgery, each rat was habituated to the maze in 5 daily sessions of $15 \mathrm{~min}$ in which the animal was allowed to explore and consume chocolate-flavored pellets that were distributed throughout the maze. In the last habituation session, the chocolate pellets were placed only in the vicinity of the reward dispensers. The experimental protocol timeline had two phases per animal of both sham and SNI groups (Fig. 1A). The first phase consisted in a training period of 10 sessions during 10 consecutive days in which only the behavioral performance was evaluated. After this period, each animal performed two recording sessions of hippocampus activity, the first one after intraperitoneal saline injection (control recording session) and the second after intraperitoneal administration of quinpirole, a dopamine D2/D3 receptor agonist $(0.05 \mathrm{mg} / \mathrm{kg}$, dissolved in saline; Sigma). The second physiology recording session was performed $10 \mathrm{~d}$ after the control session and was preceded by $2 \mathrm{~d}$ of retraining in the figure- 8 maze to keep and stabilize the performance level. In all sessions, we alternatively tested animals from control and experimental groups to prevent unpredictable bias effects. Vehicle and quinpirole were administered intraperitoneally $20 \mathrm{~min}$ in advance of the behavioral testing session. Given the extensive amount of electrophysiology sessions that are required to complete our experimental protocol, we opted to test only one drug and a single dosage. Quinpirole at $0.05 \mathrm{mg} / \mathrm{kg}$ was elected based on performance-only results from preliminary experiments in this maze, from other ongoing studies in the laboratory using a decision-making task, and from a comparative analysis of other similar studies (Horvitz et al., 2001; Huang et al., 2013). In our preliminary sessions, we found that higher doses of quinpirole $(0.1$ and $0.5 \mathrm{mg} / \mathrm{kg})$ caused severe decreases in locomotion in this task. 
A
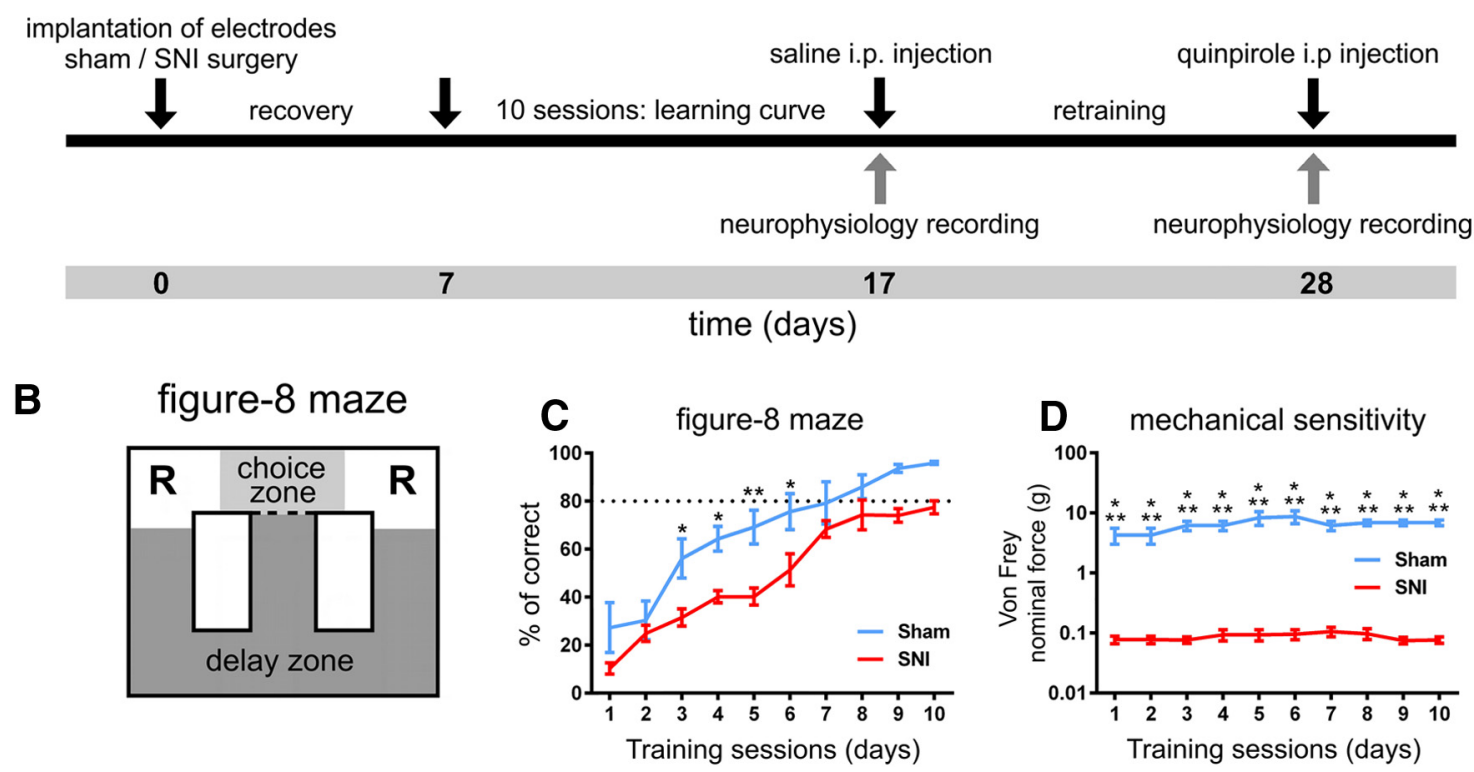

Figure 1. Experimental timeline, arena, and behavioral performance. $\boldsymbol{A}$, Timeline of experimental protocol. Briefly, each animal was implanted with multielectrode arrays in the dorsal and ventral hippocampus and subjected to a sham or SNI lesion surgery. After recovery, the animals were trained for $10 \mathrm{~d}$ and then had electrophysiological recording sessions before and after injection of quinpirole. $\boldsymbol{B}$, Diagram of the figure- 8 maze of spatial alternation used in the study. Starting from the center of the maze, the animal had to visit two reward sites ( $\mathrm{R}$ ) in alternation to obtain chocolate-flavored pellets. C, Gain in performance during the 10 training sessions. The nerve-lesioned animals (SNI: $n=7$ ) showed a significantly lower performance compared with control animals (sham: $n=4$ ). $\boldsymbol{D}$, Level of mechanical sensitivity measured by withdrawal response to stimulation with Von Frey filaments. As expected, a large decrease was observed in the threshold required to induce a paw response in SNI group and the sensitivity level was stable throughout the training period. Values are presented as mean \pm SEM. Comparisons between experimental groups are based on two-way ANOVA (group $\times$ time), followed by post hoc Bonferroni. ${ }^{*} p<0.05 ;{ }^{* *} p<0.01$; ${ }^{* * *} p<0.001$.

Electrophysiological recordings. Single-cell and local field potential (LFP) recordings were obtained from the implanted multielectrode arrays during behavioral performance in the figure- 8 maze. The 16channel multielectrode array was connected to a wireless head-stage transmitter (W16; Triangle Biosystems) that sent continuous analog signals to a Multineuron Acquisition Processor system (16-MAP' Plexon). Neural signals were preamplified $(10,000-25,000 \times)$ and digitized at 40 $\mathrm{kHz}$. Voltage-time threshold windows were used to identify single-unit waveforms and up to two neuronal action potentials per recording channel were sorted online (SortClient 2.6; Plexon) and validated by offline automatic and manual sorting techniques (Offline Sorter 2.8; Plexon) according to the cumulative criteria described in detail previously (Cardoso-Cruz et al., 2011a; Pais-Vieira et al., 2012; Cardoso-Cruz et al., 2013a). Each electrode was manually checked for artifacts (e.g., $50 \mathrm{~Hz}$ noise). Extracellular LFPs were simultaneously recorded from the same implanted microwires by low-frequency $(0.5-200 \mathrm{~Hz})$ filtering of the raw signals. LFPs were preamplified and digitized at $500 \mathrm{~Hz}$. An overhead video-tracking system (CinePlex 2; Plexon) was used to provide information about the animal position on the maze and to synchronize the video recordings with the acquired neuronal data. After the end of last recording session, the rats were deeply anesthetized with a ketamine/ xylazine mixture and the recording site was marked by injecting DC current (10-20 $\mu \mathrm{A}$ for $10-20 \mathrm{~s})$ through one microwire per array. After this step, the animals were transcardially perfused with $0.01 \mathrm{M}$ phosphate buffer, $\mathrm{pH} 7.2$, in a $0.9 \%$ saline solution, followed by $4 \%$ paraformaldehyde. Brains were removed and postfixed in $4 \%$ paraformaldehyde for $4 \mathrm{~h}$ and stored in $30 \%$ sucrose before they were frozen, sectioned into 40 $\mu \mathrm{m}$ slices, and counterstained to identify the recording sites.

$m R N A$ levels of dopamine receptors in hippocampus. Rats were deeply anesthetized by intraperitoneal injection of $200 \mathrm{mg} / \mathrm{kg}$ sodium pentobarbital solution. Brains were immediately removed after decapitation, bathed in RNALater (Ambion) for RNA preservation, and kept refrigerated during further processing. Thick coronal slabs were cut and each individual brain area was then carefully dissected under a surgical microscope, resulting in bilateral brain samples from dorsal and ventral hippocampus from 20 animals (sham, $n=10$, and SNI, $n=10 ; 21 \mathrm{~d}$ after lesion). All tissue samples were flash frozen in liquid nitrogen and stored at $-80^{\circ} \mathrm{C}$ until further processing. After mechanical tissue disruption, total RNA was isolated using the TRIzol Plus RNA Purification System (Life Technologies) according to the manufacturer's protocol; $1 \mu \mathrm{g}$ of RNA was immediately used for cDNA synthesis with the RevertAid First Strand cDNA Synthesis Kit (Thermo Fisher Scientific) according to the manufacturer's instructions. PCR amplification was performed in a StepOnePlus Real-Time PCR System (Applied Biosystems) using SYBR Select Master Mix (Applied Biosystems) and the results were analyzed using StepOne analysis software (Applied Biosystems). Real-time PCRs were performed in triplicate and the primer sequences were as follows: Drd1 (accession number NM_012546.2), 5' -TGCTGCTGGCTCCCTTTC-3' and 5' -GTTAATGCTCACCGTCTCTATGG-3'; Drd2 (accession number NM_012547.1), 5' -TGGAGGTGGTGGGTGAG-3' and 5'-CAGCAGAGTGACGATGAAGG-3'; Drd3 (accession number NM_017140.1), 5'-GTCCGCACGCCTACTACG-3' and 5' -CTCCACCTGTCACCTCCAAG-3'; Th (accession number NM_012740.3) 5' CGTCCCCAAGGTTCATC- ${ }^{\prime}$ ' and $5^{\prime}$-GGCTTCAAATGTCTCAAA TACTT-3'; Maoa (accession number NM_033653.1), 5'-CAGTATGGAAGGGTGATTCGCC- ${ }^{\prime}$ and $5^{\prime}$-CAGACCAGGCACGGAAGG-3'; Gapdh (accession number NM_017008.4), 5'-ATGATTCTACCCACGGCAAG-3' and 5'-TTCACACCCATCACAAACAT-3'. Specificity of PCRs was confirmed using the melting curves of each studied gene. Amplifications were performed starting with a 2 min step for enzyme activation at $95^{\circ} \mathrm{C}$, followed by $2 \mathrm{~min}$ at $50^{\circ} \mathrm{C}$, and 40 cycles at $95^{\circ} \mathrm{C}$ for $30 \mathrm{~s}$, $60^{\circ} \mathrm{C}$ for $45 \mathrm{~s}$, and $72^{\circ} \mathrm{C}$ for $45 \mathrm{~s}$. For each animal, semiquantitative expression of each gene of interest was performed according to the delta-Ct method, using GAPDH as housekeeping gene. Significant differences in gene expression between experimental groups were statistically assessed using a nonparametric Mann-Whitney test.

\section{Data analyses}

Behavioral data. Custom MATLAB and Python scripts were used to classify behavioral intervals based on previous or next trial outcome (correct vs error), maze navigation zone (choice and delay zones), and experimental session (sham vs SNI, vehicle vs D2/D3r-agonist treatment). 


\section{Von Frey test}

A

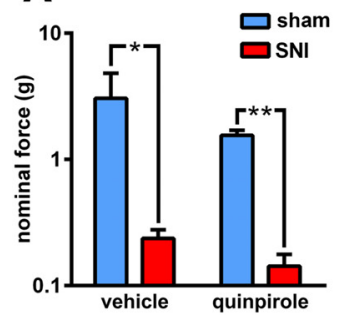

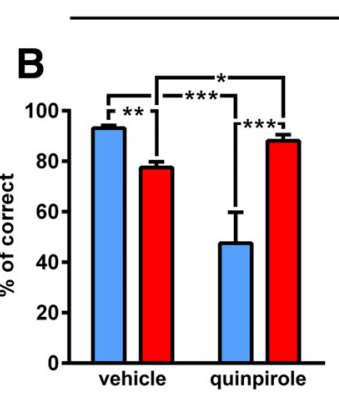

figure-8 maze

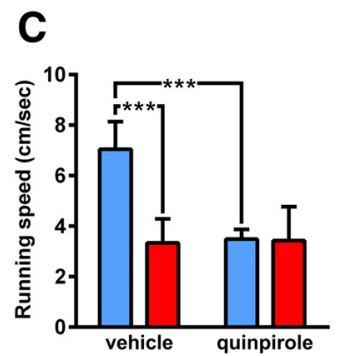

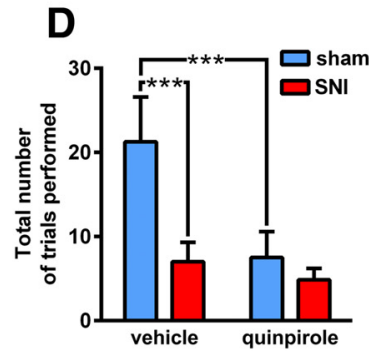

Figure 2. Effect of quinpirole injection on neuropathic nociception and behavioral performance. $A$, Quinpirole did not affect the already significant difference in mechanical threshold between sham $(n=4)$ and SNI $(n=7)$ animals. $\boldsymbol{B}$, Injection of quinpirole reversed the behavioral performance between sham and SNI animals. The percentage of completed correct alternations between reward sites was larger in the sham animals after vehicle administration, but it was larger in the SNI animals after quinpirole. The major effect of quinpirole was a decrease in the performance of the sham animals. C, Quinpirole decreased the running speed of the sham animals to the same range of the SNI animals, but did not affect the running speed of the SNI group. D, Quinpirole reduced the total number of trials (visits to the reward site after completing a full turn in the lateral corridors) executed by the sham animals. Note that despite the low number of completed trials by the SNI animals, their percentage of correct trials was larger $(\boldsymbol{B})$. Values are presented as mean \pm SEM. Comparisons between experimental groups are based on two-way ANOVA (group $\times$ treatment), followed by post hoc Bonferroni. ${ }^{*} p<0.05 ;{ }^{* *} p<0.01 ;{ }^{* * *} p<0.001$.

These classifications were calculated based on tracking navigation vectors obtained from behavior video recordings. Several parameters concerning the behavioral performance and navigation maps were examined across experimental sessions: percentage of correct alternations, total number of performed trials, and average running speed (Cardoso-Cruz et al., 2013a; Cardoso-Cruz et al., 2013b).

Spiking activity. Neural data were processed offline using NeuroExplorer 4 (NEX; Plexon) and exported to our own MATLAB R14 routines for additional analysis (MathWorks). Populational average of dCA1 and vCA1 neurons firing activity was examined across choice zone and delay zone navigation, comparing sham and SNI groups after vehicle or quinpirole administration. To characterize the temporal structure of spiking activity for correct versus error trials, population perievent time histograms were computed for each recorded region and plotted in a $2 \mathrm{~s}$ range centered at choice boundary (resolution of $50 \mathrm{~ms}$ per bin). The choice boundary was defined as the transition between central corridor and reward locations, indicated in maze diagram by the dashed black line (Fig. 1B). A two-side Kolmogorov-Smirnov (KS2) test $(p<0.05)$ was used to identify differences in the firing distributions between experimental groups. All recording sessions selected for neuronal activity comparisons had at least $5 \%$ of error trials.

LFP analysis. For statistical comparison, five bands of the LFP oscillations were considered: $1-4 \mathrm{~Hz}(\delta), 4-9 \mathrm{~Hz}(\theta), 9-15 \mathrm{~Hz}(\alpha), 15-30 \mathrm{~Hz}$ $(\beta)$, and $30-50 \mathrm{~Hz}(\gamma)$. The Kolmogorov-Smirnov (KS) test (with Dallal-Wilkinson-Lilliefor-corrected $p$-value) was used to determine whether datasets were normally distributed (Prism 6.0; GraphPad). For single comparisons, we used the nonparametric Mann-Whitney test for unpaired samples; for multiple comparisons of normally distributed samples, we used two-factor ANOVA (with post hoc Bonferroni test); and for non-normal samples, we used the non-parametric Kruskal-Wallis analysis of ranks (KW) with post hoc Dunn's test. The level of significance was set as 5\%. Results are expressed as mean \pm SEM.

Spectral analysis. Global spectral characteristics of dCA1 $\left(P_{x x}\right)$ and vCA1 $\left(P_{y y}\right)$ LFP signals were calculated in respect to choice zone and delay zone. The power spectral densities (PSD) of the LFPs signals were computed using fast Fourier transform analysis (512-point), using Welch's method as a spectral estimator (MATLAB native function) over the $0-50 \mathrm{~Hz}$ range of frequencies $(0.19 \mathrm{~Hz}$ of resolution). Histograms were smoothed using a three-point Gaussian process and are presented as percentage of total PSD in respect to frequency bands. To examine the relationship between $\theta$ power activity and behavioral performance, we plotted the averaged dCA1-vCA1 $\theta$ ratio (as dB relative to $1 \mu \mathrm{V}$ ) during choice zone navigation for all correct and error trials. To maintain a balanced number of trials per condition, only a maximum of eight correct trials per recording session were randomly selected and included for this analysis.

To measure phase coherence $\left(\Phi_{\mathrm{xy}}\right)$, hippocampus LFPs were filtered in the $\theta(4-9 \mathrm{~Hz})$ and $\gamma(30-50 \mathrm{~Hz})$ range using a zero-phase forward and reverse digital four-pole Butterworth band-pass filter to yield $\mathrm{LFP}_{\theta / \mathrm{LFP} \gamma}$. Phase coherence was then evaluated by calculating the Hilbert transform of each LFP segment. The phase angles of each signal segment were extracted and wrapped between $0^{\circ}$ and $360^{\circ}$ and are displayed as a polar plot histogram in bins of $6^{\circ}$ per segment. The Rayleigh test of uniformity $(p<0.01)$ was used to assess the resulting phase distributions for deviations from circular uniform distribution. The degree of phase coherence was determined calculating the concentration around the preferred phase in the circular distribution, with its value lying between 0 and 1 , where $\Phi_{x y}=0$ indicates that phase values at a particular frequency range are randomly distributed across the time interval and $\Phi_{x y}=1$ indicates that phase values are the same across the time interval. Phase coherence values are inversely related to the Rayleigh $p$-value, with $\Phi_{x y}=0$ standing for uniform distribution. The CircStat MATLAB toolbox (Berens, 2009) was used for circular plotting and circular statistics were calculated according to common methods (Fisher, 1993).

To determine the spectral coupling among LFP signals from recorded areas, we calculated the quadratic coherence $\left[C_{x y}(f)\right]$ applying the equation equivalent to $C_{x y}(f)=\left|P_{x y}(f)\right|^{2} /\left(P_{x x}(f) \cdot P_{y y}(f)\right)$, where the coherence is equal to the averaged cross-power spectrum $\left[P_{x y}(f)\right\}$ normalized matrix of cross-power spectral density of the two signals. A higher coherence value (near 1) indicates that phases of signals are identical and both are totally phase locked at this frequency; otherwise, lower coherence values (near 0) indicate that phases are dispersed.

The statistical method of partial directed coherence (PDC) was used to quantify the frequency-domain connectivity between dorsal and ventral hippocampus. The PDC method has been described in detail previously (Sameshima and Baccalá, 1999; Baccalá and Sameshima, 2001; CardosoCruz et al., 2011b). Briefly, PDC is an alternative representation of Granger causality involving multivariate processes to uncover direct influences in the frequency domain. Higher PDC values indicate a strong connectivity between recorded structures, which can be interpreted as the existence of information flow between them.

\section{Results}

\section{Behavioral performance}

Pain-related performance behavior

To evaluate the effect of chronic pain on spatial WM performance, we compared the controls and animals with a neuropathic pain model in a spatial alternation maze (sham control group, $n=4$; SNI group, $n=7$; Fig. 1 ). All animals of the SNItreated group developed mechanical allodynia after nerve lesion, as indicated by the von Frey filament stimulation test (Fig. 1C). Significant statistical differences were observed between groups $\left(F_{(1,90)}=161.20, p<0.0001\right)$ and training sessions $\left(F_{(9,90)}=\right.$ $3.30, p=0.0015)$. Post hoc analysis revealed that the threshold of response to stimulation in the SNI group was lower than the 
Table 1. Neuronal average firing rates of dorsal and ventral CA1 hippocampus recorded units during execution of the figure-8 maze WM task

\begin{tabular}{|c|c|c|c|c|c|c|c|c|}
\hline & \multicolumn{4}{|l|}{$\mathrm{dCA1}$} & \multicolumn{4}{|l|}{ vCA1 } \\
\hline & \multicolumn{2}{|c|}{$\begin{array}{l}\text { Sham } \\
\text { (43 neurons) }\end{array}$} & \multicolumn{2}{|c|}{$\begin{array}{l}\text { SNI } \\
\text { (57 neurons) }\end{array}$} & \multicolumn{2}{|c|}{$\begin{array}{l}\text { Sham } \\
\text { (41 neurons) }\end{array}$} & \multicolumn{2}{|c|}{$\begin{array}{l}\text { SNI } \\
\text { (56neurons) }\end{array}$} \\
\hline & Mean & SEM & Mean & SEM & Mean & SEM & Mean & SEM \\
\hline \multicolumn{9}{|l|}{ Delay zone } \\
\hline Vehicle & 4.34 & 0.29 & 4.11 & 0.14 & 5.13 & 0.31 & 5.20 & 0.21 \\
\hline Quinpirole & 3.81 & 0.31 & $5.03^{*}$ & 0.37 & 5.02 & 0.24 & 6.03 & 0.37 \\
\hline \multicolumn{9}{|l|}{ Choice zone } \\
\hline Vehicle & 5.24 & 0.34 & 4.54 & 0.51 & 5.71 & 0.28 & 6.17 & 0.11 \\
\hline Quinpirole & 5.31 & 0.28 & $6.41^{*}$ & 0.27 & 5.77 & 0.44 & 5.76 & 0.24 \\
\hline
\end{tabular}

Values represent averaged spikes per second for all of the periods that the animal spent in either the delay zone or the choice zone during the entire recording session. Comparisons between experimental groups are based on two-way ANOVA (group $\times$ treatment), followed by post hoc Bonferroni ( ${ }^{*} p<0.05$ ).

threshold of the sham group at all training sessions $(p<0.001$, Bonferroni test).

Testing sessions in the figure- 8 maze were initiated $7 \mathrm{~d}$ after the sham or SNI intervention. ANOVA indicated significant differences between groups $\left(F_{(1,90)}=14.48, p=0.0052\right)$ and across training sessions $\left(F_{(9,90)}=63.84, p<0.0001\right)$. In addition, post hoc analysis revealed a lower performance behavior of the SNI group compared with control group at day 3 (Bonferroni test, $p<0.05)$, day $4(p<0.05)$, day $5(p<0.01)$, and day $6(p<0.05$; Fig. $1 D)$. These results indicate that SNI animals had lower performance levels, particularly at early testing sessions.

Effect of quinpirole on behavioral performance

Systemic administration of quinpirole did not change pain perception thresholds significantly. ANOVA revealed differences between sham and SNI animals $\left(F_{(1,18)}=10.92, p=0.0039\right)$ and no significant effect for drug treatment $\left(F_{(1,18)}=1.56, p=0.2281\right.$; Fig. 2A).

Behavioral results in the figure- 8 maze showed an important recovery of spatial WM performance of SNI-treated animals after quinpirole administration (Fig. 2B). ANOVA revealed significant differences between experimental groups $\left(F_{(1,18)}=6.24, p=\right.$ $0.0224)$ and drug treatment $\left(F_{(1,18)}=12.25, p=0.0026\right)$. Post hoc analysis revealed that the SNI group exhibited an increase of performance after quinpirole administration $(p<0.05$, Bonferroni test), whereas the sham group had an opposite effect $(p<0.001)$.

An essential issue of spatial alternation tasks success is the motor performance. We found significant differences between experimental groups in terms of running speed parameter during maze navigation $\left(F_{(1,18)}=10.02, p=0.0054\right)$ and drug treatment $\left(F_{(1,18)}=8.49, p=0.0093\right)$. Moreover, post hoc analysis revealed that running speed of SNI-treated group were lower compared with sham for vehicle administration, as expected ( $p<0.001$; Fig. $2 C)$. It is important to note that quinpirole injection induces a decline of motor activity; however, that reduction was not correlated with performance impairment in the SNI group. In fact, SNI animals after quinpirole injection illustrated better performance even with lower navigation running speed. This premise were also supported by the total number of trials performed per session in the figure- 8 maze after quinpirole injection, which for SNI animals were reduced but had a better performance ratio (Fig. $2 D)$. Data from the total number of performed trials showed clear differences between experimental groups $\left(F_{(1,18)}=13.06, p=\right.$ $0.0020)$ and a significant effect for treatment factor $\left(F_{(1,18)}=\right.$ $11.56, p=0.0032)$. Post hoc analysis revealed a decrease in the total number of trials performed per session in SNI-treated animals compared with sham animals for vehicle administration

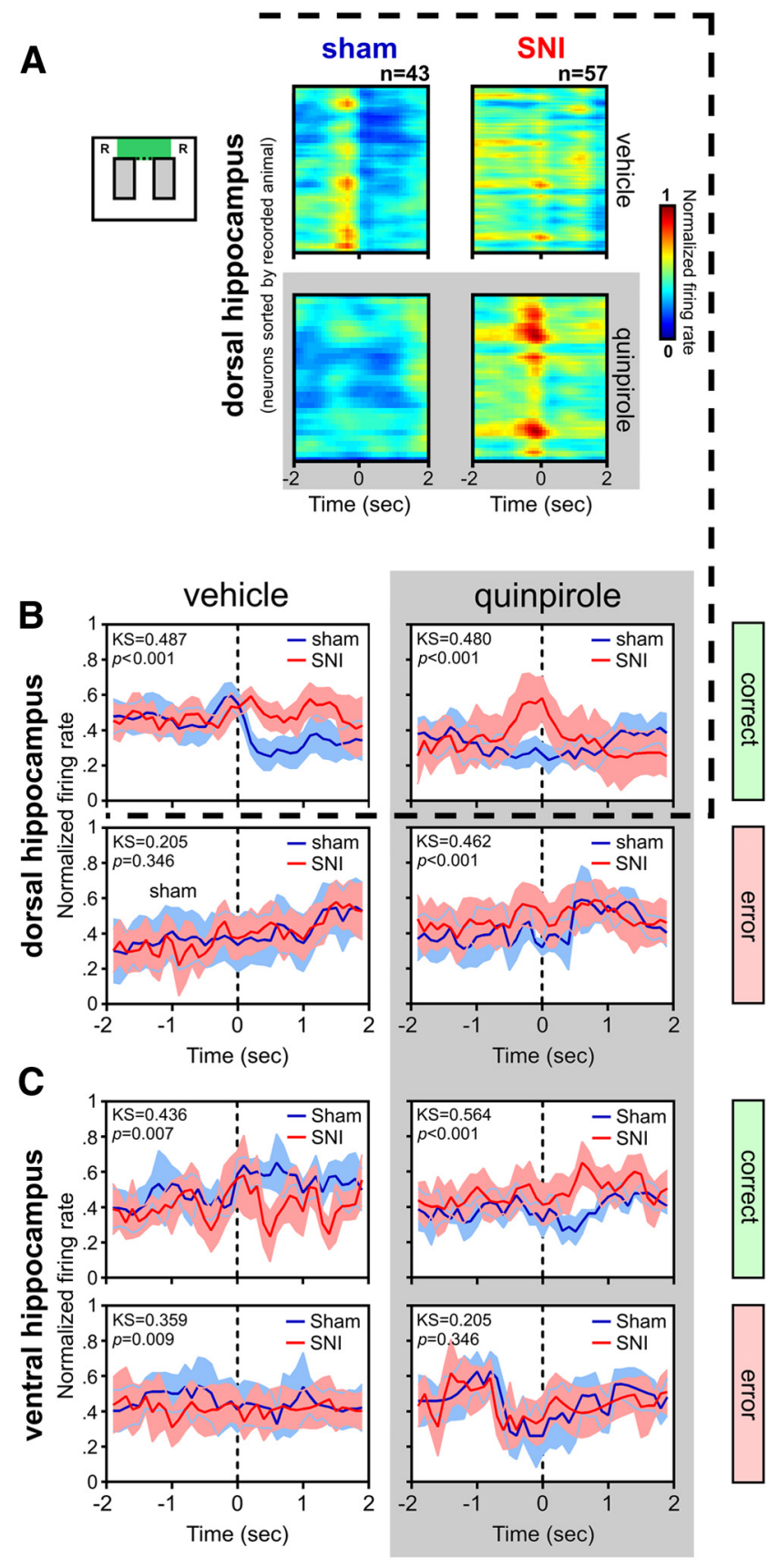

Figure 3. Peridecision neuronal activity during correct and error trials. A, Color-coded raster plots of neuronal activity (bin resolution of $50 \mathrm{~ms}$ ) for all dorsal hippocampus recorded neurons during the $4 \mathrm{~s}$ period centered in themoment of crossing from the delay to the choicearea in the figure-8maze during correct trials. dCA1 neurons of sham animals presenta peak of neuronal firing rate immediately preceding the approach of the decision point thatisfollowed by a sudden decrease in firing rate. In contrast, dCA1 neurons of SNl animals showa more stable firing rateduring the peridecision period. Injection of quinpirolereverses this electrophysiological pattern, with the SNI animals now presenting a peak of activity and sham animals showing a stable firing rate. $B, C$, Detailed peridecision histograms of population neuronal activity for both dorsal $(\boldsymbol{B})$ and ventral ( $C$ hippocampus during either correct (top) or error (bottom) trials. Values are presented as mean \pm SEM. Comparisons of firing distributions of experimental groups are based on the KS2 test; $p<0.05$.

( $p<0.001$, Bonferroni test) and also indicateda similar response after quinpirole treatment shared by both experimental groups (Fig. 2D).

\section{Neuronal activity}

Hippocampal firing patterns during behavioral performance

A total of 197 neurons were recorded from dorsal (dCA1, $n=100$ cells) and ventral hippocampus (vCA1, $n=97$ cells). Table 1 
A

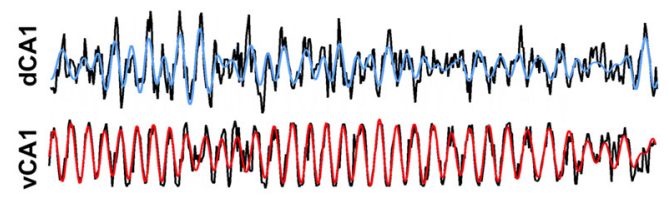

B
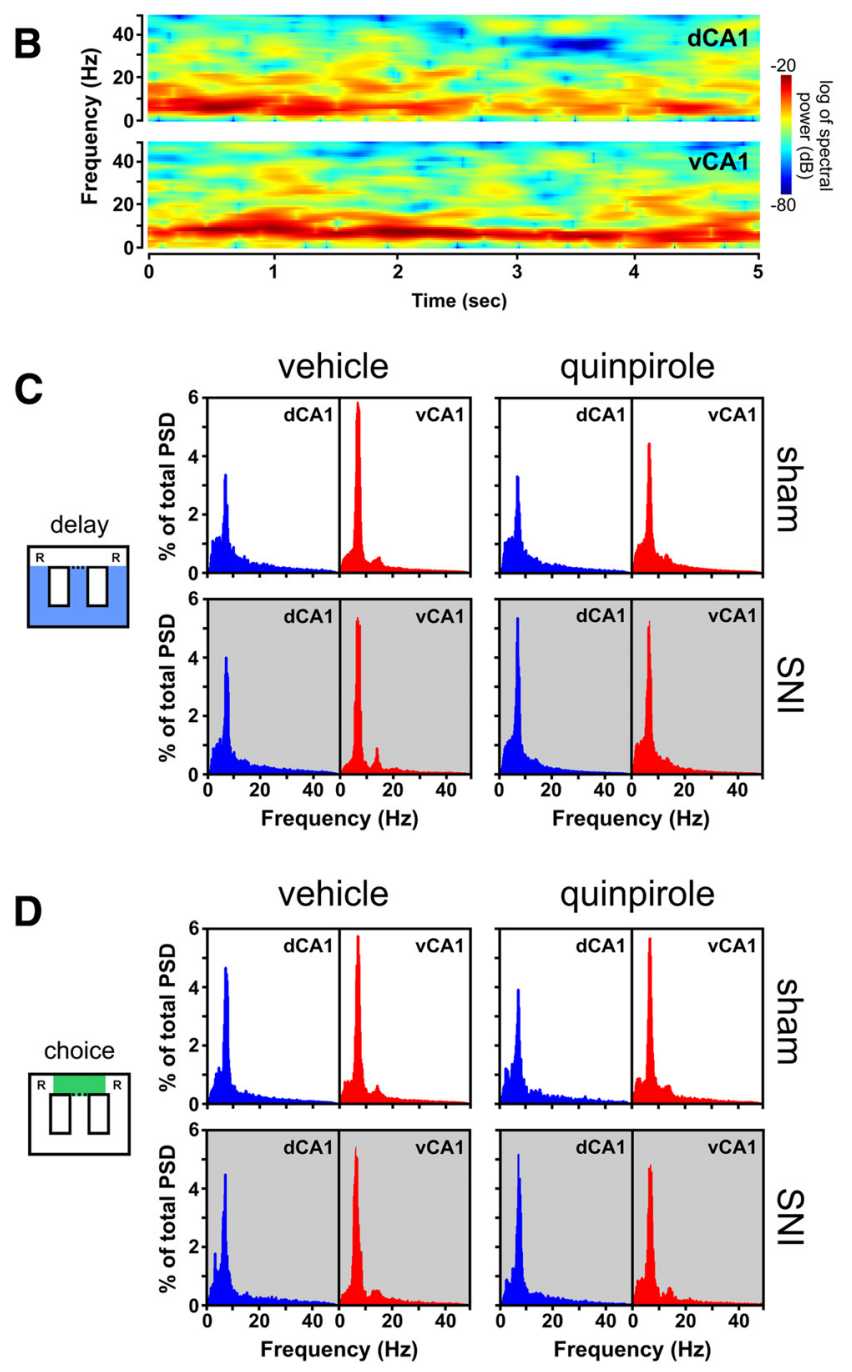

Figure 4. Spectral analysis of dorsal and ventral CA1 hippocampus LFP signals. $A$, Example trace of raw recording representing 5 s of ongoing LFP activity in a sham animal recorded during delay zone navigation. Blue trace represent the dorsal hippocampus $\theta$ filtered signal $(4-9 \mathrm{~Hz})$, whereas the red trace represent the ventral hippocampus $\theta$ filtered signal $(4-9 \mathrm{~Hz})$; the black traces undern each colored trace are the unfiltered LFP signal of each area. $\boldsymbol{B}$, Full spectrograms for the same example of 5 s recording used in $A$ show the predominance of $\theta$ oscillations in both areas of the hippocampus during active navigation. $\boldsymbol{C}, \boldsymbol{D}$, Power spectra density plots of dorsal and ventral LFP activity during navigation in the delay zone $(\boldsymbol{C})$ and choice zone $(\boldsymbol{D})$ for both sham $(n=4)$ and SNI $(n=7)$ animals. Data were calculated for each entire recording session independently of correct or error trials. PSD traces show that quinpirole does not affect the overall pattern of $\theta$ predominance.

presents the averaged populational firing rate activity for the two recorded hippocampal areas. In the case of dCA1, significant differences were observed between experimental groups (delay zone: $F_{(1,196)}=6.12, p=0.0142$; choice zone: $F_{(1,196)}=3.73, p=$ $0.0495)$ and pharmacological treatment (delay zone: $F_{(1,196)}=$ $3.85, p=0.0428$; choice zone: $\left.F_{(1,196)}=7.21, p=0.007\right)$. Quinpirole administration caused an increase of firing rate in dCA1 neurons in SNI-treated animals (both navigation zones $p<0.05$, Bonferroni test). For vCA1 neurons, no significant differences
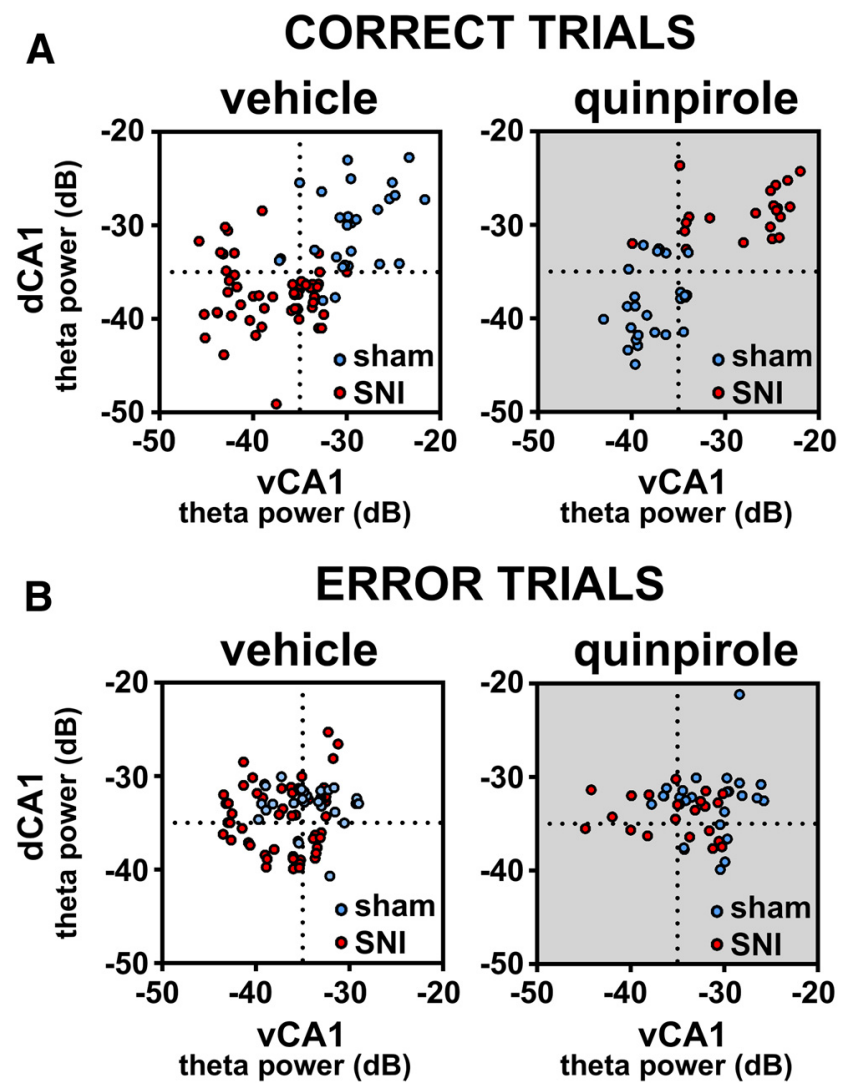

Figure 5. Dissociation between dorsal and ventral CA1 field $\theta$ power activity during correct and error trials. Scatter plots of the distribution of dorsoventral $\theta$ ratios per trials of sham (blue dots) and SNI animals (red dots). $A$, During correct trials, sham animals presented higher $\theta$ power in dorsal hippocampus, whereas SNI animals presented higher $\theta$ power in ventral hippocampus; this pattern of dorsoventral ratio was reversed by quinpirole (shaded scatter plot in A). $\boldsymbol{B}$, In contrast, the during error trials, there was no preferential dorsoventral $\theta$ ratio in either groups of animals before or after the administration of quinpirole.

were observed in either behavioral task between experimental groups (delay zone: $F_{(1,190)}=3.24, p=0.0735$; choice zone: $\left.F_{(1,190)}=0.69, p=0.4075\right)$ or after pharmacological treatments (delay zone: $F_{(1,190)}=1.44, p=0.2316$; choice zone: $F_{(1,190)}=$ $0.42, p=0.5193)$.

Firing activity in correct and error trials

To analyze whether the firing activity was affected when the animal approached the point of decision between the two alternative reward locations, we calculated the population activity by recorded area for either correct or error trials for each animal (Fig. $3)$. The spiking activity for both dCA1 and vCA1 neurons revealed different temporal activity patterns centered at the choice line of the maze in which the animals decided between left or right turn. Our data showed that sham animals present an increase of population firing rate of dCA1 neurons immediately preceding the arrival at the point of left/right decision, and that this decision-related increase in activity was abolished by the quinpirole administration (Fig. $3 A$, top rasters). Interestingly, dCA1 neurons of SNI group of animals presented the inverse results, with an increase of firing rate occurring only after the administration of quinpirole (Fig. $3 A$, bottom raster). Statistical analysis of the normality of the temporal profiles of neuronal activity showed that, in the dCA1, there were differences in the firing rate between experimental groups during the correct trials (vehicle: $\mathrm{KS} 2=0.487, p<0.001$; quinpirole: $\mathrm{KS} 2=0.480, p<$ 

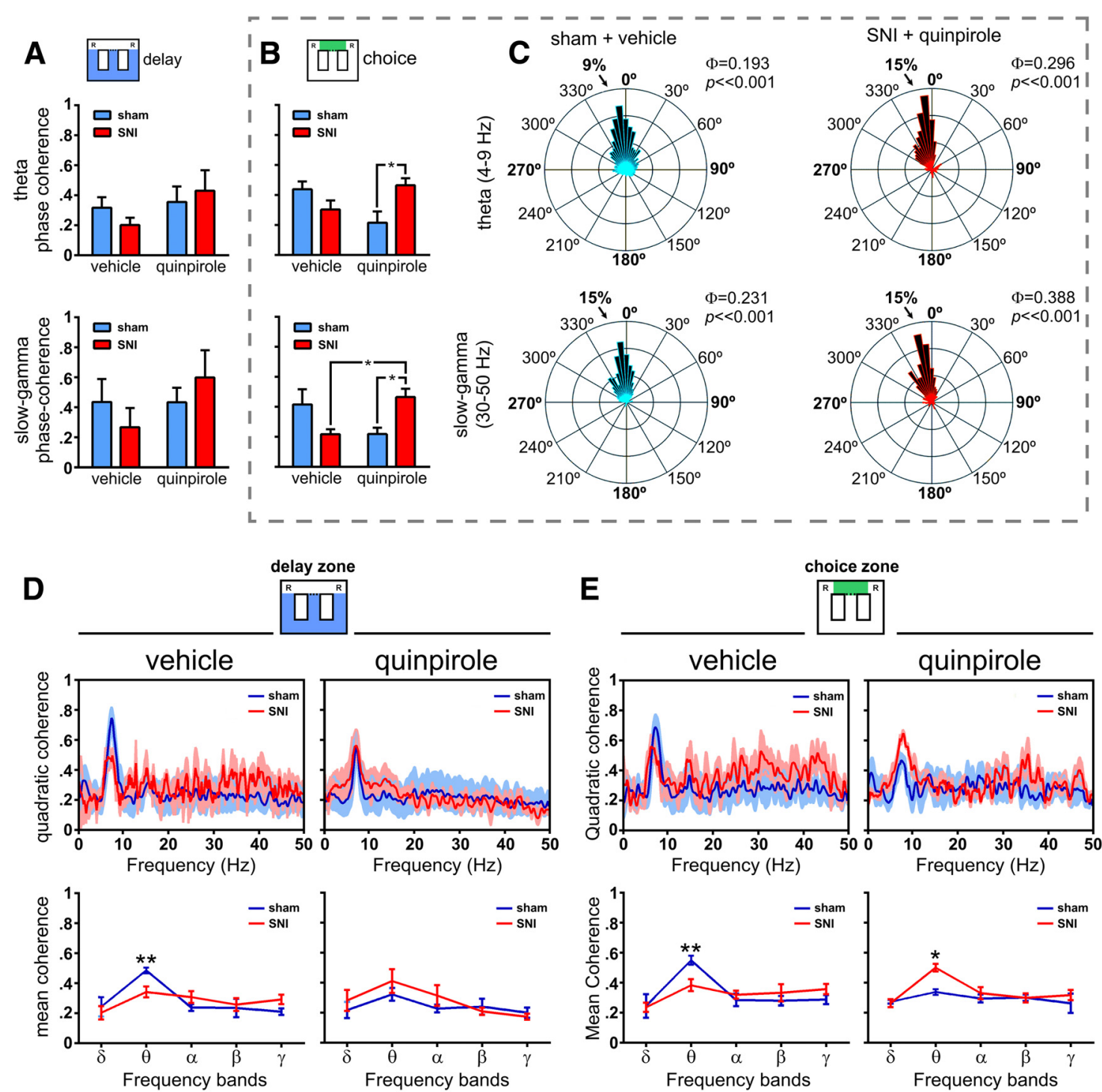

Figure 6. Spectral analysis of $\theta$ and $\gamma \mathrm{LFP}$ activity in dorsal and ventral hippocampus during maze navigation. $\boldsymbol{A}, \boldsymbol{B}, \mathrm{dCA1}-\mathrm{vCA} 1$ phase coherence $(\Phi)$ activity for $\theta(4-9 \mathrm{~Hz})$ and $\gamma(30-50 \mathrm{~Hz})$ frequency bands during delay and choice zones navigation. No significant differences were observed in delay zone between experimental groups or quinpirole administration $(A)$. In contrast, during choice zone navigation (B), quinpirole reversed the phase coherence between sham and SNI animals in both the $\theta$ and $\gamma$ bands of frequency. C, Examples of rose plots of LFP phase distributions after vehicle (in a sham animal) and quinpirole (in an SNI animal). The number in the upper right corner of each rose plot represents the value of $\Phi$. All circular concentration distributions are significantly nonuniform (Rayleigh test, $p<0.01$ ). D, E, Spectral quadratic coherence between CA1 and VCA1 LFP signals show in all cases a strong coherence in the $\theta$ band of frequency (top). Detailed analysis of the quadratic coherence per band of frequency (bottom) shows that sham animals in both areas of maze have the largest $\theta$ quadratic coherence, whereas after quinpirole, the maximal $\theta$ coherence occurs in the $\mathrm{SNI}$ animals. Frequency bands: $\delta, 1-4 \mathrm{~Hz} ; \theta, 4-9 \mathrm{~Hz} ; \alpha, 9-15 \mathrm{~Hz} ; \beta, 15-30 \mathrm{~Hz} ; \gamma, 30-50 \mathrm{~Hz}$. Values are presented as mean \pm SEM. Comparisons between experimental groups are based on two-way ANOVA (group $\times$ treatment) or (group $\times$ frequency band), followed by post hoc Bonferroni. ${ }^{*} p<0.05{ }^{* * *} p<0.01$.

0.001 ; Fig. $3 B$, top row), and also during the error trials, but only after quinpirole treatment $(\mathrm{KS} 2=0.462, p<0.001$; Fig. $3 B$, bottom row). In the case of the vCA1 neurons, our data showed differences between experimental groups during the correct trials (vehicle: $\mathrm{KS} 2=0.436, p=0.007$; quinpirole: $\mathrm{KS} 2=0.564, p<$ 0.001; Fig. $3 C$, top row), whereas during the error trials, there were differences in the firing rate only after vehicle injection $(\mathrm{KS} 2=0.359, p=0.009$; Fig. $3 C$, bottom row $)$.

\section{Spectral analysis}

Changes in PSDs

The qualitative comparison of PSD values for sham and SNI groups in function of drug treatment and maze navigation zones revealed the expected profile of power oscillations with the major power peak occurring in the $\theta$ frequency band $(4-9 \mathrm{~Hz})$ in both recorded areas. The administration of quinpirole also did not cause major differences in the PSD profile (Fig. 4).

To analyze whether the $\theta$ rhythm was affected with the performance of the animal, we calculated the $\theta$ power ratio and the absolute value of the $\theta$ power difference between the signals of the $\mathrm{dCA} 1$ and vCA1 from correct versus error trials (Fig. 5). Interestingly, the plots of the dCA1/vCA1 $\theta$ ratio show that sham and SNI groups do not have overlapping power ratios during the correct trials (Fig. 5A), but they overlap during error trials (Fig. 5B). Moreover, the administration of quinpirole did not affect the separation of $\theta$ ratios during the correct and the overlap during the error trials, although it reversed the magnitude of the power ratios, with the SNI animals presenting larger $\theta$ power ratios in both areas after quinpirole during correct trials (Fig. $5 A, B$ ). 

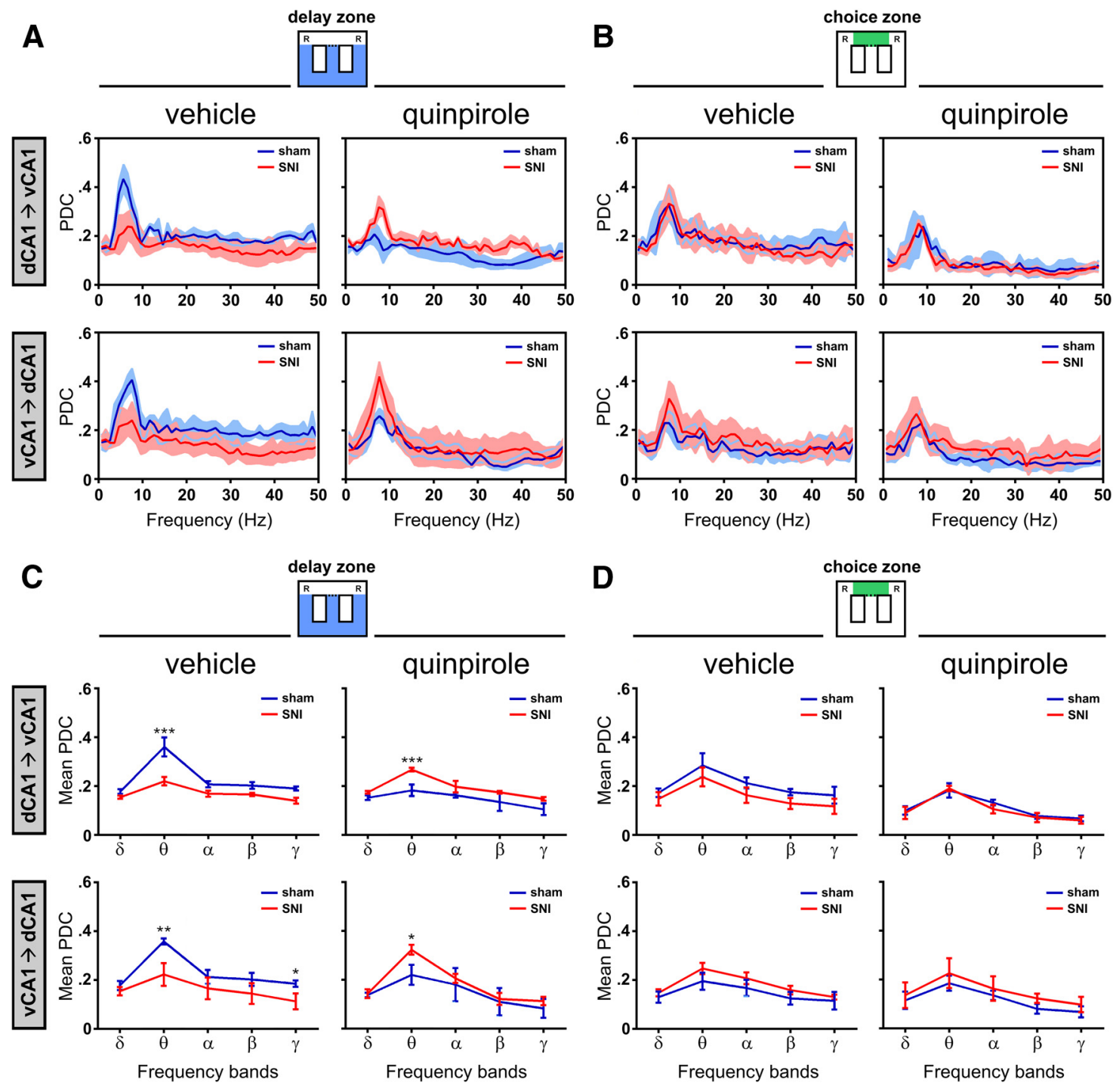

Figure 7. Dorsoventral functional connectivity during maze navigation. $A, B$, Bidirectional traces of PDC across the spectral range of frequencies for both the sham and SNI groups before and after quinpirole administration. In all cases, there is a peak of $P D C$ values in the $\theta$ range, reflecting that hippocampus dorsoventral functional connectivity is particularly important in this band of frequency. $C, D$, Bidirectional analysis of PDC per band of frequencies in both sham and SNI groups before and after quinpirole administration. The functional connectivity is only different between experimental groups during navigation in the delay zone, not in the choice zone. During navigation in the delay zone, quinpirole reversed the functional connectivity between experimental groups: before quinpirole, the sham animals presented the largest dorsoventral connectivity, whereas after quinpirole, the largest connectivity occurs in the $\mathrm{SNl}$ animals. Frequency bands: $\delta, 1-4 \mathrm{~Hz} ; \theta, 4-9 \mathrm{~Hz}$; $\alpha, 9-15 \mathrm{~Hz} ; \beta, 15-30 \mathrm{~Hz} ; \gamma, 30-50 \mathrm{~Hz}$. Values are presented as mean \pm SEM. Comparisons between experimental groups are based on two-way ANOVA (group $\times$ frequency band), followed by post hoc Bonferroni. ${ }^{*} p<0.05 ;{ }^{* *} p<0.01 ;{ }^{* *} p<0.001$.

LFP phase coherence in dorsoventral hippocampus

To determine whether $\theta$ and $\gamma$ oscillations were modulated by the behavioral flexibility required for strategic navigation, we performed phase coherence analyses of LFP signals from correct trials. Our results showed no statistical differences during navigation in the delay zone (Fig. 6A); however, during navigation in the choice area, we found significant differences between groups $\left(\theta: F_{(1,18)}=6.28, p=0.0220 ; \gamma: F_{(1,18)}=6.47, p=0.0204\right)$ and between pharmacological treatments $\left(\theta: F_{(1,18)}=9.40, p=\right.$ $0.0066 ; \gamma: F_{(1,18)}=13.89, p=0.0015$; Fig. $\left.6 B\right)$. Post hoc analyses indicated an enhancement of $\theta$ and $\gamma$ phase coherence (both $p<$ 0.05 , Bonferroni test) after quinpirole injection in SNI-treated animals compared with the control group (Fig. 6B). Illustrative examples of phase distributions are given in Figure $6 C$. The rose plot histograms cover a narrow range of phase coherence for $\theta$ and $\gamma$ frequencies (all phase distributions are significantly non- uniform, $p<0.01$ Rayleigh test), suggesting a broader coordination of hippocampal activities during decision-making processes.

\section{LFPs coherence in dorsoventral hippocampus}

The quadratic coherence between dorsal and ventral FLP signals was separately quantified for periods of navigation in delay or choice zones. In all cases, the peak of dCA1::vCA1 coherence occurred at the $\theta$ frequency band (Fig. $6 D, E$ ).

In the analysis per frequency bands, our data showed no statistical differences between experimental groups (delay zone: $F_{(1,45)}=0.03, p=0.8626$; choice zone: $\left.F_{(1,45)}=0.06, p=0.8132\right)$, but a significant effect between frequency bands (delay zone: $F_{(4,45)}=35.98, p<0.0001$; choice zone: $F_{(4,45)}=50.66, p<$ $0.0001)$; post hoc analyses revealed that, after saline injection, the sham group presented higher $\theta$ coherence in both navigation areas (delay zone: $p<0.01$; and choice zone: $p<0.01$; Fig. $6 D, E$, 
A

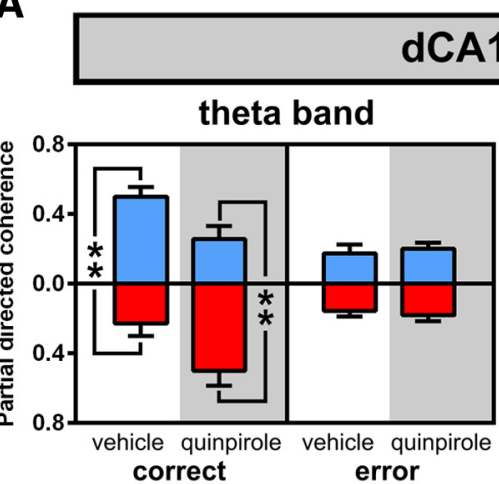

B $\mathrm{vCA} 1 \rightarrow \mathrm{dCA} 1$
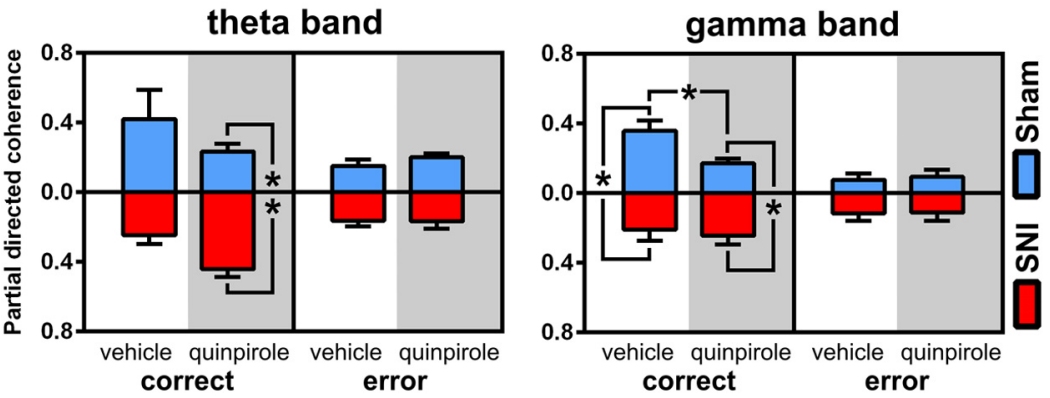

Figure 8. Differences in dorsoventral functional connectivity between correct and error trials. $A, B$, Values of bidirectional PDC separated by group, treatment, and correct versus error trials. The separation of correct from error trials reveal distinct patterns of connectivity: whereas during correct trials, there are high connectivity PDC values in $\theta$ and $\gamma$ bands and a quinpirole-induced reversal of connectivity between sham and SNI animals (as described previously in Fig. 7), the error trials are characterized by low dorsoventral connectivity, no difference between sham or SNI animals, and no change after quinpirole administration. Frequency bands: $\theta, 4-9 \mathrm{~Hz} ; \gamma, 30-50 \mathrm{~Hz}$. Values are presented as mean $\pm \mathrm{SEM}$. Comparisons between experimental groups are based on nonparametric Kruskal-Wallis test, followed by Dunn's post hoc test for multiple comparisons. ${ }^{*} p<0.05 ;{ }^{* *} p<0.01$.

bottom row). In contrast, quinpirole injection reversed the levels of dorsoventral hippocampus coherence and the SNI animals presented higher levels of coherence than sham animals; we found a difference between groups during navigation in the choice zone $\left(F_{(1,45)}=4.72, p=0.0351\right)$ and differences across frequency bands for both navigation zones (delay zone: $F_{(4,45)}=$ 9.87, $p<0.0001$; and choice zone: $\left.F_{(4,45)}=5.63, p=0.0009\right)$. In contrast to vehicle administration, post hoc analysis revealed an increase of $\theta$ oscillations coherence activity for SNI-treated animals during choice zone navigation ( $p<0.05$; Fig. $6 D$, E, bottom row).

Modulation of hippocampus dorsoventral functional connectivity The occurrence of high coherence between two LFP signals suggests synchronization, but does not disambiguate whether the synchrony is due to synchronous fluctuations in power or to consistent maintenance of phase relationships. To further study the time-frequency-dependent relationship between the dorsal and ventral regions of hippocampus, we estimated the level of functional connectivity by PDC analysis (Baccalá and Sameshima, 2001). The quantification of bidirectional PDC levels between recorded regions during task navigation is presented in Figure 7 and clearly shows that changes in circuit connectivity occurred mainly at the $\theta$ frequency band.

In the case of vehicle administration, significant differences were observed between groups (dCA1 to vCA1 direction: delay zone: $F_{(1,45)}=36.46, p<0.0001$; choice zone: $F_{(1,45)}=25.20, p<$
0.0001; vCA1 to dCA1 direction: delay zone: $F_{(1,45)}=51.21, p<0.0001$; choice zone: $\left.F_{(1,45)}=4.40, p=0.0417\right)$, as well as across frequency bands (dCA1 to vCA1 direction: delay zone: $F_{(4,45)}=23.75, p<$ 0.0001; choice zone: $F_{(4,45)}=25.84, p<$ $0.0001 ; \mathrm{vCA} 1$ to $\mathrm{dCA} 1$ direction: delay zone: $F_{(4,45)}=28.57, p<0.0001$; choice zone: $F_{(4,45)}=5.89, p=0.0007$; Fig. $7 C, D)$. Moreover, post hoc analysis revealed a decrease of PDC activity of SNItreated animals compared with control animals in the delay zone (dCA1 to vCA1 direction: $\theta, p<0.001$; vCA1 to dCA1 direction: $\theta, p<0.01, \gamma, p<0.05$; Fig. $7 C$ ).

Importantly, quinpirole injection reversed the levels of intrahippocampus functional connectivity by increasing the abnormally reduced connectivity in SNI animals to levels close to that observed in normal conditions (cf. Fig. $7 C, D$, left vs right, respectively). ANOVA showed statistical differences between groups (dCA1 to vCA1 direction: delay zone: $F_{(1,45)}=$ 31.49, $p<0.0001$; vCA1 to dCA1 direction: delay zone: $F_{(1,45)}=6.16, p=$ 0.0159; choice zone: $F_{(1,45)}=8.31, p=$ 0.0060 ), and between frequency bands (dCA1 to vCA1 direction: delay zone: $F_{(4,45)}=49.07, p<0.0001$; choice zone: $F_{(4,45)}=12.69, p<0.0001 ; \mathrm{vCA} 1$ to dCA1 direction: delay zone: $F_{(4,45)}=19.62, p<$ 0.0001 ; and choice zone: $F_{(4,45)}=14.47$, $p<0.0001)$.

Hippocampus dorsoventral connectivity in correct and error trials

We expanded the analysis of decision-related neuronal activity by separating correct from error trials and repeating the PDC analysis, now focusing only on the $\theta$ and $\gamma$ frequency bands. The results presented in Figure 8 show that the PDC levels of functional connectivity were in all cases larger in the correct versus error trials; similarly, all of the PDC differences were observed in the signals from the correct trials, with the majority of differences occurring in the sham versus SNI comparison rather than on the vehicle versus quinpirole administration. In the dCA1 to vCA1 direction, statistical significances were obtained for experimental groups in the $\theta$ frequency band (KW $=19.11, p=0.0003$ ). Post hoc analysis revealed a decrease in SNI versus sham animals $(p<$ 0.01; Dunn's test) and an increase in SNI after quinpirole treatment $(p<0.01$; Fig. $8 A$ ). In the vCA1 to dCA1 direction, data showed differences in the $\theta(\mathrm{KW}=19.29, p=0.0002)$ and $\gamma$ frequencies during correct trials $(\mathrm{KW}=15.89, p=0.0012$; Fig. $8 B$ ). Post hoc analysis revealed that SNI animals increased their $\theta$ connectivity level in respect to sham animals after quinpirole administration ( $p<0.01$; Dunn's test), whereas in the $\gamma$ band, there was a difference in the sham versus SNI comparison (vehicle: $p<0.05$; quinpirole: $p<0.05$ ) and a reduction of connectivity in the sham animals in the vehicle versus quinpirole comparison $(p<0.05)$.

$m R N A$ levels of DA receptors in dorsal and ventral hippocampus Finally, we evaluated whether the neuropathic pain condition could produce changes in the expression of DA receptors mRNA 

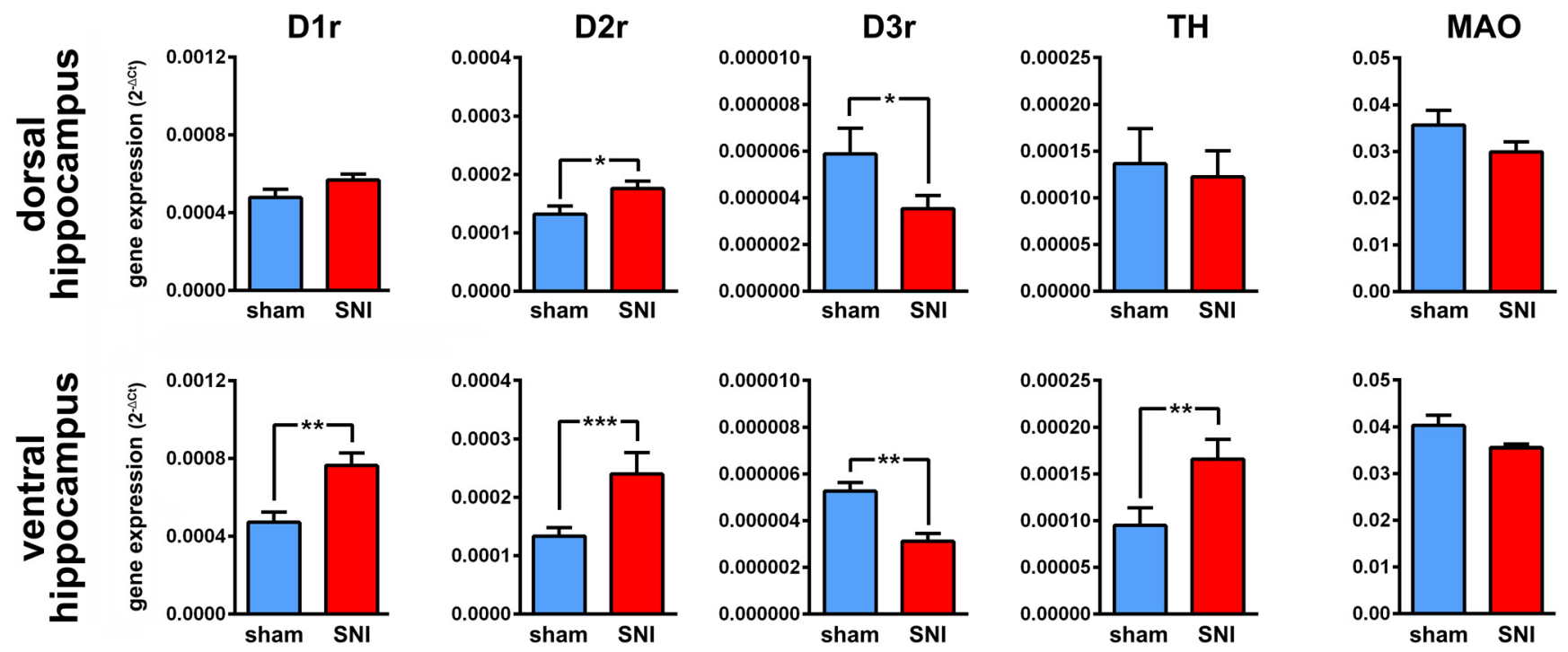

Figure 9. Nerve injury associated changes in dopamine-related gene expression in dorsal and ventral hippocampus. Gene expression was assessed by real-time PCR using GAPDH as a housekeeping gene. Each bar represents the average of individual tissue samples run separately (10 animals per group). Comparisons between experimental groups are based on nonparametric Mann-Whitney test for unpaired samples. TH, tyrosine hydroxylase; MA0, monoamine oxidase A. ${ }^{*} p<0.05$; $^{* *} p<0.01$; $^{* * *} p<0.001$.

levels in the hippocampus CA1 field. This quantification was done in a separate group of animals ( We observed an increase in the mRNA levels of the dopamine D1 receptor in the ventral hippocampus (Mann-Whitney $U$ test $=6$, $p=0.0047)$, an increase in the D2 receptor in both areas (dCA1: $U=72, p=0.0350$; vCA1: $U=43, p=0.0009$ ), a decrease in the D3 receptor in both areas (dCA1: $U=64, p=0.0151$; $\mathrm{vCA} 1: U=$ $2, p=0.0097$ ), and finally an increase in the tyrosine hydroxylase in the ventral hippocampus $(U=55, p=0.0051$; Fig. 9).

\section{Discussion}

In this study, we report how the induction of chronic neuropathic pain affects neuronal activity and LFP reward-related oscillations across the dorsoventral axis of the hippocampus while rats performed a spatial alternation WM task. We report that the peripheral nerve lesion caused a disruption in WM performance and that the activation of dopamine D2/D3 receptors by systemic quinpirole restored the behavioral performance and the neurophysiological patterns of hippocampus activity to the range observed in sham animals. We also report that peripheral nerve injury changes the gene expression of dopamine receptors and modulators in dorsal and ventral hippocampus, suggesting that disruption of the hippocampus dopaminergic system is an important side effect that may be crucial for the clinical neurological deficits observed in patients with painful neuropathic syndromes.

Mesencephalic dopaminergic innervation of the hippocampus terminates in both the dorsal and ventral hippocampus (Gasbarri et al., 1997), with a larger predominance of ventral tegmental area and substantia nigra afferents in the ventral CA1 (Verney et al., 1985; Gasbarri et al., 1994). Previous studies have also demonstrated that dopamine D2 receptor (D2r) is abundant in the ventral hippocampus region and that D2r agonist injection in this region can restore memory impairment via D2r-acetylcholine interactions (Fujishiro et al., 2005). Moreover, 6-hydroxydopamine lesions of hippocampal dopaminergic innervations cause selective deficits in spatial WM (Gasbarri et al., 1996), whereas the present and previous studies have shown that the administration of the dopamine D2/D3 receptor agonist quinpirole improves both memory performance (Gasbarri et al., 1993; Wilkerson and Levin, 1999), and memory retention (Packard and White, 1991). Future studies will be needed to fully ascertain whether direct intrahippocampus application of quinpirole administered systemically has the same effect that we describe here.

Electrophysiological studies have shown that dopamine receptors have differential effects over the expression of LTP depending on the brain region of interest: activation of $\mathrm{D} 2 \mathrm{r}$ enhances LTP in the amygdala and dentate gyrus but not in CA1 (Frey et al., 1989; Manahan-Vaughan and Kulla, 2003; Amano et al., 2008), whereas LTP in striatum is enhanced by the blockade of D2 receptors (Calabresi et al., 1997). Conversely, activation of D1r promotes LTP across all tested brain areas and is particularly well studied in hippocampus CA1 (Frey et al., 1990; Frey et al., 1991). This distinct effect of each dopamine receptor certainly results from different regional distributions (Meador-Woodruff et al., 1991; Weiner et al., 1991; Bruinink and Bischoff, 1993), especially from the opposite effect that D1-like and D2-like receptors have on intracellular cAMP production and subsequent PKA and DARPP-32 signaling (Greengard et al., 1999; Neve et al., 2004).

Our present results are in agreement with the hypothesis that chronic pain causes a wide-brain decrease in dopamine levels and changes in dopaminergic signaling (Wood, 2006; Pais-Vieira et al., 2009; Wood et al., 2009), because the administration of a D2 agonist reversed the behavioral and neurophysiological alterations induced by the onset of the SNI neuropathic pain model. This effect was particularly visible in the restoring of peridecision peak of neuronal firing rate during correct alternations that was abolished in the SNI animals (Fig. 3). Therefore, our results support the notion that the dopaminergic system is crucial for reward-related learning in the hippocampus network (Pennartz et al., 2011; Baudonnat et al., 2013). It is well known that dopaminergic modulation of hippocampus activity affects performance in spatial learning tasks (O'Carroll et al., 2006; Granado et al., 2008) and disrupts the stability of hippocampus place cells (Martig and Mizumori, 2011) and that VTA inactivation sup- 
presses CA1 LTP (Ghanbarian and Motamedi, 2013). It has also been reported recently that the dorsal hippocampus conveys relevant information to the VTA concerning goal-directed behaviors to promote the rapid activation of dopaminergic neurons and improve the context response (Luo et al., 2011).

Only a few studies have addressed the issue of information spread along the dorsoventral axis of the hippocampus by simultaneously recording both areas in awake unrestrained animals (Sabolek et al., 2009; Royer et al., 2010; Patel et al., 2012; Penley et al., 2013; Schmidt et al., 2013). Overall, these previous studies have shown that, during decision making, the $\theta$ power presents an increase in dorsal hippocampus and a decrease in ventral hippocampus, whereas the coherence between both areas increases only when new spatial learning occurs; both observations are also confirmed by the present results. Moreover, our present study expands previous results by showing the role that dopaminergic modulation plays in restoring the correct balance of dorsoventral connectivity in chronic pain animals. In addition, we found differences in dorsoventral $\theta$ power ratios between trials with correct and incorrect performance (Fig. 5); curiously, quinpirole administration reversed the $\theta$ ratios in correct trials but did not affect the ratios in the incorrect trials, suggesting that episodic performance errors may result from instantaneous changes in dorsoventral balance of activity. This effect was also extended to dorsoventral CA1 LFP spectral coherence activity, particularly in $\theta$ frequency. A similar intensification of $\theta$ coherence across hippocampal and frontal regions has been described during the execution of WM tasks using human EEG recording (Tesche and Karhu, 2000; Onton et al., 2005) and these patterns were greatest just before a correct decision (Jones and Wilson, 2005). In addition, $\theta$ oscillations can interact with other frequencies-namely $\gamma$ oscillations - and this interplay has been associated to a possible hippocampal control mechanism for temporal segregation of information to other brain regions during memory processing (Colgin et al., 2009). To further study the relationship of activity between the dorsal and ventral hippocampal CA1 fields, we calculated the information flow dynamics using PDC analysis, which revealed that the main changes in dorsoventral functional connectivity occurred in $\theta$ oscillations.

A final note should be given on the recent insights that have demonstrated a central role for dopaminergic neurotransmission modulating pain perception and analgesia within supraspinal regions. There is ample evidence from animal models that DA plays a critical role in antinociception. This occurs primarily via activation of dopamine $\mathrm{D} 2$ receptors in ventral striatum/nucleus accumbens (Altier and Stewart, 1999), and insular cortex (Coffeen et al., 2010). Microinjection of quinpirole within nucleus accumbens and dorsolateral striatum inhibits the persistent phase of formalin-induced nociception in a dose-dependent fashion and this effect is blocked by preadministration of the selective D2r receptor antagonist raclopride (Altier and Stewart, 1999). Lesion of striatal dopaminergic terminals significantly decreases latencies of several nociceptive reflexes and accelerates the time of onset of chronic deafferentation pain after peripheral neurectomy (Saadé et al., 1997). Bilateral VTA lesion also enhances pain-related behaviors (Sotres-Bayón et al., 2001), whereas stimulation of the VTA-substantia nigra produces analgesia (Sarkis et al., 1984; Sotres-Bayón et al., 2001). Together, these results suggest that dopamine depletion results in hypersensitive mechanical pain thresholds and that modulation of dopamine receptors is an important component of pain perception.

In summary, we show here that changes in dorsoventral hippocampus CA1 neuronal activity are associated with the impair- ment in spatial WM performance that occurs after a peripheral nerve injury and that this behavioral disruption is reversed by systemic administration of the D2/D3 receptor agonist quinpirole. Further characterization of the role that dopaminergic modulation plays in hippocampus activity of chronic pain syndromes may be clinically relevant for the understanding of the cognitive impairment that accompanies nociceptive stressful conditions (Moriarty et al., 2011).

\section{References}

Aguiar P, Mendonça L, Galhardo V (2007) OpenControl: a free opensource software for video tracking and automated control of behavioral mazes. J Neurosci Methods 166:66-72. CrossRef Medline

Altier N, Stewart J (1999) The role of dopamine in the nucleus accumbens in analgesia. Life Sci 65:2269-2287. CrossRef Medline

Amano T, Wada E, Yamada D, Zushida K, Maeno H, Noda M, Wada K, Sekiguchi M (2008) Heightened amygdala long-term potentiation in neurotensin receptor type-1 knockout mice. Neuropsychopharmacology 33:3135-3145. CrossRef Medline

Arnsten AF, Cai JX, Steere JC, Goldman-Rakic PS (1995) Dopamine D2 receptor mechanisms contribute to age-related cognitive decline: the effects of quinpirole on memory and motor performance in monkeys. J Neurosci 15:3429-3439. Medline

Baccalá LA, Sameshima K (2001) Partial directed coherence: a new concept in neural structure determination. Biol Cybern 84:463-474. CrossRef Medline

Bannerman DM, Yee BK, Good MA, Heupel MJ, Iversen SD, Rawlins JN (1999) Double dissociation of function within the hippocampus: a comparison of dorsal, ventral, and complete hippocampal cytotoxic lesions. Behav Neurosci 113:1170-1188. CrossRef Medline

Baudonnat M, Huber A, David V, Walton ME (2013) Heads for learning, tails for memory: reward, reinforcement and a role of dopamine in determining behavioral relevance across multiple timescales. Front Neurosci 7:175. CrossRef Medline

Berens P (2009) CircStat: a MATLAB toolbox for circular statistics. Journal of Statistical Software 31:1.

Bruinink A, Bischoff S (1993) Dopamine D2 receptors are unevenly distributed in the rat hippocampus and are modulated differently than in striatum. Eur J Pharmacol 245:157-164. CrossRef Medline

Cai JX, Arnsten AF (1997) Dose-dependent effects of the dopamine D1 receptor agonists A77636 or SKF81297 on spatial working memory in aged monkeys. J Pharmacol Exp Ther 283:183-189. Medline

Calabresi P, Saiardi A, Pisani A, Baik JH, Centonze D, Mercuri NB, Bernardi G, Borrelli E (1997) Abnormal synaptic plasticity in the striatum of mice lacking dopamine D2 receptors. J Neurosci 17:4536-4544. Medline

Cardoso-Cruz H, Lima D, Galhardo V (2011a) Instability of spatial encoding by CA1 hippocampal place cells after peripheral nerve injury. Eur J Neurosci 33:2255-2264. CrossRef Medline

Cardoso-Cruz H, Sameshima K, Lima D, Galhardo V (2011b) Dynamics of circadian thalamocortical flow of information during a peripheral neuropathic pain condition. Front Integr Neurosci 5:43. CrossRef Medline

Cardoso-Cruz H, Lima D, Galhardo V (2013a) Impaired spatial memory performance in a rat model of neuropathic pain is associated with reduced hippocampus-prefrontal cortex connectivity. J Neurosci 33:2465-2480. CrossRef Medline

Cardoso-Cruz H, Sousa M, Vieira JB, Lima D, Galhardo V (2013b) Prefrontal cortex and mediodorsal thalamus reduced connectivity is associated with spatial working memory impairment in rats with inflammatory pain. Pain 154:2397-2406. CrossRef Medline

Castner SA, Williams GV, Goldman-Rakic PS (2000) Reversal of antipsychoticinduced working memory deficits by short-term dopamine D1 receptor stimulation. Science 287:2020-2022. CrossRef Medline

Chaplan SR, Bach FW, Pogrel JW, Chung JM, Yaksh TL (1994) Quantitative assessment of tactile allodynia in the rat paw. J Neurosci Methods 53:5563. CrossRef Medline

Coffeen U, Ortega-Legaspi JM, de Gortari P, Simón-Arceo K, Jaimes O, Amaya MI, Pellicer F (2010) Inflammatory nociception diminishes dopamine release and increases dopamine D2 receptor mRNA in the rat's insular cortex. Mol Pain 6:75. CrossRef Medline

Colgin LL, Denninger T, Fyhn M, Hafting T, Bonnevie T, Jensen O, Moser 
MB, Moser EI (2009) Frequency of gamma oscillations routes flow of information in the hippocampus. Nature 462:353-357. CrossRef Medline

Decosterd I, Woolf CJ (2000) Spared nerve injury: an animal model of persistent peripheral neuropathic pain. Pain 87:149-158. CrossRef Medline

Dong HW, Swanson LW, Chen L, Fanselow MS, Toga AW (2009) Genomic-anatomic evidence for distinct functional domains in hippocampal field CA1. Proc Natl Acad Sci U S A 106:11794-11799. CrossRef Medline

Fanselow MS, Dong HW (2010) Are the dorsal and ventral hippocampus functionally distinct structures? Neuron 65:7-19. CrossRef Medline

Fisher NI (1993) Statistical analysis of circular data: Cambridge UP.

Frey U, Hartmann S, Matthies H (1989) Domperidone, an inhibitor of the D2-receptor, blocks a late phase of an electrically induced long-term potentiation in the CA1-region in rats. Biomed Biochim Acta 48:473-476. Medline

Frey U, Schroeder H, Matthies H (1990) Dopaminergic antagonists prevent long-term maintenance of posttetanic LTP in the CA1 region of rat hippocampal slices. Brain Res 522:69-75. CrossRef Medline

Frey U, Matthies H, Reymann KG, Matthies H (1991) The effect of dopaminergic D1 receptor blockade during tetanization on the expression of long-term potentiation in the rat CA1 region in vitro. Neurosci Lett 129: 111-114. CrossRef Medline

Fujishiro H, Umegaki H, Suzuki Y, Oohara-Kurotani S, Yamaguchi Y, Iguchi A (2005) Dopamine D2 receptor plays a role in memory function: implications of dopamine-acetylcholine interaction in the ventral hippocampus. Psychopharmacology (Berl) 182:253-261. CrossRef

Gasbarri A, Introini-Collison IB, Packard MG, Pacitti C, McGaugh JL (1993) Interaction of cholinergic-dopaminergic systems in the regulation of memory storage in aversively motivated learning tasks. Brain Res 627:7278. CrossRef Medline

Gasbarri A, Verney C, Innocenzi R, Campana E, Pacitti C (1994) Mesolimbic dopaminergic neurons innervating the hippocampal formation in the rat: a combined retrograde tracing and immunohistochemical study. Brain Res 668:71-79. CrossRef Medline

Gasbarri A, Sulli A, Innocenzi R, Pacitti C, Brioni JD (1996) Spatial memory impairment induced by lesion of the mesohippocampal dopaminergic system in the rat. Neuroscience 74:1037-1044. CrossRef Medline

Gasbarri A, Sulli A, Packard MG (1997) The dopaminergic mesencephalic projections to the hippocampal formation in the rat. Prog Neuropsychopharmacol Biol Psychiatry 21:1-22. CrossRef Medline

Ghanbarian E, Motamedi F (2013) Ventral tegmental area inactivation suppresses the expression of CA1 long term potentiation in anesthetized rat. PLoS ONE 8:e58844. CrossRef Medline

Granado N, Ortiz O, Suárez LM, Martin ED, Ceña V, Solís JM, Moratalla R (2008) D1 but not D5 dopamine receptors are critical for LTP, spatial learning, and LTP-Induced arc and zif268 expression in the hippocampus. Cereb Cortex 18:1-12. CrossRef Medline

Greengard P, Allen PB, Nairn AC (1999) Beyond the dopamine receptor: the DARPP-32/protein phosphatase-1 cascade. Neuron 23:435-447. CrossRef Medline

Horvitz JC, Williams G, Joy R (2001) Time-dependent actions of D2 family agonist quinpirole on spontaneous behavior in the rat: dissociation between sniffing and locomotion. Psychopharmacology (Berl) 154:350355. CrossRef Medline

Huang JJ, Yen CT, Liu TL, Tsao HW, Hsu JW, Tsai ML (2013) Effects of dopamine D2 agonist quinpirole on neuronal activity of anterior cingulate cortex and striatum in rats. Psychopharmacology (Berl) 227:459466. CrossRef Medline

Jones MW, Wilson MA (2005) Phase precession of medial prefrontal cortical activity relative to the hippocampal theta rhythm. Hippocampus 15: 867-873. CrossRef Medline

Kjelstrup KG, Tuvnes FA, Steffenach HA, Murison R, Moser EI, Moser MB (2002) Reduced fear expression after lesions of the ventral hippocampus. Proc Natl Acad Sci U S A 99:10825-10830. CrossRef Medline

Lisman J, Grace AA, Duzel E (2011) A neoHebbian framework for episodic memory; role of dopamine-dependent late LTP. Trends Neurosci 34: 536-547. CrossRef Medline

Luo AH, Tahsili-Fahadan P, Wise RA, Lupica CR, Aston-Jones G (2011) Linking context with reward: a functional circuit from hippocampal CA3 to ventral tegmental area. Science 333:353-357. CrossRef Medline

Manahan-Vaughan D, Kulla A (2003) Regulation of depotentiation and long-term potentiation in the dentate gyrus of freely moving rats by dopamine D2-like receptors. Cereb Cortex 13:123-135. CrossRef Medline

Martig AK, Mizumori SJ (2011) Ventral tegmental area disruption selectively affects CA1/CA2 but not CA3 place fields during a differential reward working memory task. Hippocampus 21:172-184. CrossRef Medline

Meador-Woodruff JH, Mansour A, Healy DJ, Kuehn R, Zhou QY, Bunzow JR, Akil H, Civelli O, Watson SJ Jr (1991) Comparison of the distributions of D1 and D2 dopamine receptor mRNAs in rat brain. Neuropsychopharmacology 5:231-242. Medline

Moriarty O, McGuire BE, Finn DP (2011) The effect of pain on cognitive function: a review of clinical and preclinical research. Prog Neurobiol 93:385-404. CrossRef Medline

Moser MB, Moser EI (1998) Functional differentiation in the hippocampus. Hippocampus 8:608-619. CrossRef Medline

Neve KA, Seamans JK, Trantham-Davidson H (2004) Dopamine receptor signaling. J Recept Signal Transduct Res 24:165-205. CrossRef Medline

O'Carroll CM, Martin SJ, Sandin J, Frenguelli B, Morris RG (2006) Dopaminergic modulation of the persistence of one-trial hippocampusdependent memory. Learn Mem 13:760-769. CrossRef Medline

Onton J, Delorme A, Makeig S (2005) Frontal midline EEG dynamics during working memory. Neuroimage 27:341-356. CrossRef Medline

Packard MG, White NM (1991) Dissociation of hippocampus and caudate nucleus memory systems by posttraining intracerebral injection of dopamine agonists. Behav Neurosci 105:295-306. CrossRef Medline

Pais-Vieira M, Mendes-Pinto MM, Lima D, Galhardo V (2009) Cognitive impairment of prefrontal-dependent decision-making in rats after the onset of chronic pain. Neuroscience 161:671-679. CrossRef Medline

Pais-Vieira M, Aguiar P, Lima D, Galhardo V (2012) Inflammatory pain disrupts the orbitofrontal neuronal activity and risk-assessment performance in a rodent decision-making task. Pain 153:1625-1635. CrossRef Medline

Patel J, Fujisawa S, Berényi A, Royer S, Buzsáki G (2012) Traveling theta waves along the entire septotemporal axis of the hippocampus. Neuron 75:410-417. CrossRef Medline

Paxinos G, Watson C (1998) The rat brain in stereotaxic coordinates. San Diego: Academic.

Penley SC, Hinman JR, Long LL, Markus EJ, Escabí MA, Chrobak JJ (2013) Novel space alters theta and gamma synchrony across the longitudinal axis of the hippocampus. Front Syst Neurosci 7:20. CrossRef Medline

Pennartz CM, Ito R, Verschure PF, Battaglia FP, Robbins TW (2011) The hippocampal-striatal axis in learning, prediction and goal-directed behavior. Trends Neurosci 34:548-559. CrossRef Medline

Rainer G, Miller EK (2000) Effects of visual experience on the representation of objects in the prefrontal cortex. Neuron 27:179-189. CrossRef Medline

Royer S, Sirota A, Patel J, Buzsáki G (2010) Distinct representations and theta dynamics in dorsal and ventral hippocampus. J Neurosci 30:17771787. CrossRef Medline

Saadé NE, Atweh SF, Bahuth NB, Jabbur SJ (1997) Augmentation of nociceptive reflexes and chronic deafferentation pain by chemical lesions of either dopaminergic terminals or midbrain dopaminergic neurons. Brain Res 751:1-12. CrossRef Medline

Sabolek HR, Penley SC, Hinman JR, Bunce JG, Markus EJ, Escabi M, Chrobak JJ (2009) Theta and gamma coherence along the septotemporal axis of the hippocampus. J Neurophysiol 101:1192-1200. CrossRef Medline

Sameshima K, Baccalá LA (1999) Using partial directed coherence to describe neuronal ensemble interactions. J Neurosci Methods 94:93-103. CrossRef Medline

Sarkis D, Souteyrand JP, Albe-Fessard D (1984) Self-stimulation in the ventral tegmental area suppresses self-mutilation in rats with forelimb deafferentiation. Neurosci Lett 44:199-204. CrossRef Medline

Schmidt B, Hinman JR, Jacobson TK, Szkudlarek E, Argraves M, Escabí MA, Markus EJ (2013) Dissociation between dorsal and ventral hippocampal theta oscillations during decision-making. J Neurosci 33:6212-6224. CrossRef Medline

Sotres-Bayón F, Torres-López E, López-Avila A, del Angel R, Pellicer F (2001) Lesion and electrical stimulation of the ventral tegmental area modify persistent nociceptive behavior in the rat. Brain Res 898:342-349. CrossRef Medline

Swanson LW, Cowan WM (1977) An autoradiographic study of the organi- 
zation of the efferent connections of the hippocampal formation in the rat. J Comp Neurol 172:49-84. CrossRef Medline

Takahashi H, Kato M, Takano H, Arakawa R, Okumura M, Otsuka T, Kodaka F, Hayashi M, Okubo Y, Ito H, Suhara T (2008) Differential contributions of prefrontal and hippocampal dopamine $\mathrm{D}(1)$ and $\mathrm{D}(2)$ receptors in human cognitive functions. J Neurosci 28:12032-12038. CrossRef Medline

Tesche CD, Karhu J (2000) Theta oscillations index human hippocampal activation during a working memory task. Proc Natl Acad Sci U S A 97: 919-924. CrossRef Medline

Thompson CL, Pathak SD, Jeromin A, Ng LL, MacPherson CR, Mortrud MT, Cusick A, Riley ZL, Sunkin SM, Bernard A, Puchalski RB, Gage FH, Jones AR, Bajic VB, Hawrylycz MJ, Lein ES (2008) Genomic anatomy of the hippocampus. Neuron 60:1010-1021. CrossRef Medline

Verney C, Baulac M, Berger B, Alvarez C, Vigny A, Helle KB (1985) Morphological evidence for a dopaminergic terminal field in the hippocampal formation of young and adult rat. Neuroscience 14:1039-1052. CrossRef Medline

Weiner DM, Levey AI, Sunahara RK, Niznik HB, O’Dowd BF, Seeman P, Brann MR (1991) D1 and D2 dopamine receptor mRNA in rat brain. Proc Natl Acad Sci U S A 88:1859-1863. CrossRef Medline
Wilkerson A, Levin ED (1999) Ventral hippocampal dopamine D1 and D2 systems and spatial working memory in rats. Neuroscience 89:743-749. CrossRef Medline

Witter MP, Amaral DG (2004) Hippocampal formation. In: The rat nervous system, Ed 3 (Paxinos G, ed), pp 635-704. London: Elsevier.

Wood PB (2006) Mesolimbic dopaminergic mechanisms and pain control. Pain 120:230-234. CrossRef Medline

Wood PB, Patterson JC 2nd, Sunderland JJ, Tainter KH, Glabus MF, Lilien DL (2007a) Reduced presynaptic dopamine activity in fibromyalgia syndrome demonstrated with positron emission tomography: a pilot study. J Pain 8:51-58. CrossRef Medline

Wood PB, Schweinhardt P, Jaeger E, Dagher A, Hakyemez H, Rabiner EA, Bushnell MC, Chizh BA (2007b) Fibromyalgia patients show an abnormal dopamine response to pain. Eur J Neurosci 25:3576-3582. CrossRef Medline

Wood PB, Glabus MF, Simpson R, Patterson JC 2nd (2009) Changes in gray matter density in fibromyalgia: correlation with dopamine metabolism. J Pain 10:609-618. CrossRef Medline

Zimmermann M (1983) Ethical guidelines for investigations of experimental pain in conscious animals. Pain 16:109-110. CrossRef Medline 